INFLAMMATORY BOWEL DISEASE

\title{
Impact of the increasing use of immunosuppressants in Crohn's disease on the need for intestinal surgery
}

\author{
J Cosnes, I Nion-Larmurier, L Beaugerie, P Afchain, E Tiret, J-P Gendre
}

Gut 2005;54:237-241. doi: 10.1136/gut.2004.045294

See end of article for authors' affiliations

Correspondence to: Pr Jacques Cosnes, Hôpital Saint-Antoine, 184 rue du Faubourg St-Antoine,

75571 Paris cedex 12,

France; jacques.cosnes@ sat.ap-hop-paris.fr

Accepted for publication 3 June 2004
Background/Aim: Immunosuppressants are now used much earlier in the course of Crohn's disease; however their effect on the natural history of the disease, especially on the need for surgery, is not known. The aim of this study was to assess the evolution of the need for surgery in Crohn's disease during the last 25 years.

Patients and Methods: The medical charts of 2573 patients were reviewed retrospectively. The use of immunosuppressants (azathioprine or methotrexate), the need for intestinal resection, and the occurrence of intestinal complications were assessed using Kaplan-Meier analysis in five consecutive cohorts of patients defined by the date of diagnosis of Crohn's disease (1978-82; 1983-87; 1988-92; 1993-97; 1998-2002).

Results: In 565 patients seen in the authors' unit within the first three months after diagnosis, characteristics of Crohn's disease at diagnosis did not differ from one cohort to another. The five year cumulative probability to receive immunosuppressants increased from 0 in the 1978-82 cohort to $0.13,0.25,0.25$, and 0.56 in the 1983-87, 1988-92, 1993-97, and 1998-2002 cohorts, respectively $(p<0.001)$. Concomitantly, the cumulative risk of intestinal resection remained unchanged (from 0.35 to 0.34 at five years; $p=0.81)$. The cumulative risk of developing a stricturing or a penetrating intestinal complication remained also unchanged. Similar results were obtained in the 2008 patients seen during the same period who were referred to us more than three months after diagnosis.

Conclusion: Although immunosuppressants have been used more frequently over the last 25 years, there was no significant decrease of the need for surgery, or of intestinal complications of Crohn's disease.
$\mathrm{T}$ he treatment strategy for Crohn's disease $(\mathrm{CD})$ is evolving. ${ }^{1}$ Steroids and 5 -aminosalicylates are still commonly used; however, during recent years there have been some significant changes. Firstly, the remarkable efficacy and the overall good tolerance of immunosuppressants were recognised ${ }^{2-5}$ and when compared with the morbidity of untreated disease, ${ }^{6}$ led to their wider greater use. Some authors even proposed using immunosuppressants from the very beginning of the disease, with the objective to modify its natural history, ${ }^{7}$ and this strategy has been shown to improve disease course and to avoid steroids in children with moderate to severe disease. ${ }^{8}$ Secondly, anti-tumour necrosis factor therapy became available in the late 1990s. Infliximab was shown to be able to induce clinical remission in patients unresponsive to standard treatment, ${ }^{\text {' }}$ to clear anatomic damage, and, when used as maintenance treatment, to maintain clinical remission ${ }^{10}$ and fistula closure. ${ }^{11}$

However, the impact of an increasing use of immunosuppressants and novel therapies on the natural history of CD remains poorly evaluated. An important and unbiased criterion for assessing the overall severity of CD is the need for surgery: for decades there has been a consensus to limit surgery to complications and refractory intractable forms.

The aim of our study, performed in a large series of patients with CD, was to evaluate the effect upon the need for surgery of an increasing use of immunosuppressants over the last 25 years.

\section{PATIENTS AND METHODS \\ Patients}

Patients with CD who were seen consecutively in our unit between January 1978 and December 2002 were included retrospectively. In January 2003, our unit moved from Rothschild hospital to St-Antoine Hospital and recruitment for this study was interrupted. Diagnosis of CD was based on Lennard-Jones criteria. ${ }^{12}$ Two groups of patients were analysed. The first group consisted of 565 patients who were seen in our unit early in the course of their disease-within the first three months following diagnosis of CD. The time of diagnosis was defined as the date of first detection of unequivocal inflammatory abnormalities of the intestine, as assessed from radiological, endoscopic, or peroperative observations. Patients in the second group $(n=2008)$ were seen more than three months after diagnosis, being referred to us for various reasons. Within each group, patients were divided into five consecutive five year cohorts, according to the date of diagnosis: cohorts 1978-82, 1983-87, 1988-92, 1993-97, and 1998-2002.

\section{Study design}

The study analysed the evolution of surgical requirements over 25 years by comparing the need for excisional surgery in relation to the use of immunosuppressants among the five chronologic cohorts. Only excisional intestinal surgery was taken into account. Appendectomy, stricturoplasty, bypass, and elective surgical treatment of abscess were not considered. The time to first intestinal resection was the main outcome criteria. In addition were noted the time to first large intestinal resection-either alone or cumulative, defined by a post-surgical index equal or superior to $20,{ }^{13}$ and the time to establishment of a definitive stoma. The postsurgical handicap index has been developed to predict the functional consequences of intestinal resection for CD. It is calculated from operative records, taking into account the location and extent of intestinal resection. An index score equal or superior to 20 has a high predictive value of

Abbreviations: $C D$, Crohn's disease; HR, hazard ratio. 
diarrhoea following intestinal resection. ${ }^{13}$ Intestinal complications of $\mathrm{CD}$ were defined according to the Vienna classification: intestinal strictures as the occurrence of constant luminal narrowing demonstrated by radiological, endoscopic, or surgical examination combined with prestenotic dilatation and/or obstructive signs or symptoms but without evidence of penetrating disease. ${ }^{14}$ Perforations were intra-abdominal fistulas, inflammatory masses, and/or abscesses. ${ }^{14}$ First morphological demonstration of narrowing or penetrating complication was used to date the occurrence of the complication.

\section{Treatment of Crohn's disease}

Our treatment policy has been described elsewhere. ${ }^{15}$ Flare up episodes were treated with mesalamine (3-4 g daily) or prednisolone ( $1 \mathrm{mg} / \mathrm{kg}$ per day, progressively tapered after four weeks), according to their clinical severity. When steroid therapy failed, patients seen before 1999 were given a three week course of enteral or parenteral nutrition; those seen after June 1999 (when infliximab became available in France) received infliximab $5 \mathrm{mg} / \mathrm{kg}$.

As maintenance treatment, we used aminosalicylates (sulphasalazine, olsalazine, or mesalamine, 2-3 g daily) for asymptomatic or moderately active forms of the disease, and immunosuppressive drugs for severe forms (patients who were steroid dependent or poorly responsive to steroids). Azathioprine $2 \mathrm{mg} / \mathrm{kg}$ per day was used as the first line immunosuppressive drug. In case of repeated flare-ups or chronic active disease in a patient receiving azathioprine, its dosage was increased to $2.5-3 \mathrm{mg} / \mathrm{kg}$ per day. Intramuscular methotrexate (20-25 mg weekly) was used in patients unresponsive or intolerant to azathioprine. Its dosage was tapered progressively to $10-15 \mathrm{mg}$, and re-augmented in case of clinical relapse.

Although the overall strategy remained mostly unchanged, over time there was a clear tendency to initiate immunosuppressants earlier in the disease course.

Surgery was reserved for stenotic and extraparietal complications, or intractable forms after a well conducted medical management.

\section{Statistical analysis}

Continuous data are expressed as median (interquartile range), and differences between cohorts were tested for significance by ANOVA. Discrete data are given as percentages, and comparisons were made with Pearson $\chi^{2}$ test. Kaplan-Meier survival analysis was used to estimate the cumulative probability of needing immunosuppressants or surgery after diagnosis. Survival curves were compared by means of a two sided log rank test. A Cox proportional hazards regression model with a backward variable elimination procedure was used to assess the strength of the associations while controlling for possible confounding variables. All baseline variables suspected to be possible predictors of intestinal surgery (age, sex, initial disease location (upper GI tract, jejunal, ileal, colonic, rectal, or anoperineal lesions), smoking status, appendectomy, familial history, ethnicity (White, North-African non-Jewish ancestry), geographic origin outside Paris area, and calendar period of diagnosis (before or after 30 June 1990)), were entered into the model. Results of analysis are presented as hazard ratios (HRs) with 95\% confidence intervals. Calculations were performed using GB-STAT statistical software (Silver Spring, MD, USA).

\section{RESULTS}

The characteristics of $\mathrm{CD}$ at diagnosis in the five cohorts of group 1 are given in table 1 . Patients were very similar at diagnosis from one cohort to another, with a predominance of females, a mean age about 30 years, a large proportion of smokers (half the patients), and a similar disease location. Table 2 gives the cumulative characteristics of the disease at the end of 2003. No attempt was made to contact the patients at that time and $31 \%$ of them had been lost to follow up. Because patients from the oldest cohorts had a longer disease duration, they developed more stricturing or penetrating complications and were classified so according to Vienna classification. ${ }^{16}$ Similarly, the respective proportions of patients needing steroids or immunosuppressants, and operated on, should be interpreted in relation to different durations of follow up. Azathioprine was maintained for a prolonged period in most cases but had to be stopped within the first month because of adverse events in 16 patients $(11 \%)$. It was switched to methotrexate in eight of those latter patients.

\section{Changes in the use of immunosuppressants over 25 years in group 1 patients}

Figure 1 shows the cumulative use of immunosuppressants in the five cohorts. Data of patients for whom immunosuppressants had to be stopped early are included. As expected, immunosuppressants have been used more and more early over the last 25 years, with a five year cumulative probability

\begin{tabular}{|c|c|c|c|c|c|}
\hline & $\begin{array}{l}\text { Cohort } \\
1978-82\end{array}$ & $\begin{array}{l}\text { Cohort } \\
1983-87\end{array}$ & $\begin{array}{l}\text { Cohort } \\
1988-92\end{array}$ & $\begin{array}{l}\text { Cohort } \\
1993-97\end{array}$ & $\begin{array}{l}\text { Cohort } \\
\text { 1998-2003 }\end{array}$ \\
\hline Patients (n) & 34 & 46 & 102 & 176 & 207 \\
\hline Males & $15(44)$ & $24(52)$ & $38(37)$ & $71(40)$ & $73(35)$ \\
\hline $\begin{array}{l}\text { Median age (interquartile } \\
\text { range) }\end{array}$ & $25(21-35)$ & $27(21-38)$ & $27(20-37)$ & $29(22-38)$ & $27(20-36)$ \\
\hline \multicolumn{6}{|l|}{ Disease location } \\
\hline lleocolonic & $13(38)$ & $19(41)$ & $41(40)$ & $60(34)$ & $72(35)$ \\
\hline Small bowel & $11(32)$ & $16(35)$ & $32(31)$ & $59(34)$ & $70(34)$ \\
\hline Colon & $7(21)$ & $10(22)$ & $27(26)$ & $52(30)$ & $60(29)$ \\
\hline Other & 3 (9) & $1(2)$ & $2(2)$ & $5(3)$ & $5(2)$ \\
\hline Appendectomised & $13(38)$ & $20(43)$ & 35 (34) & $49(28)$ & $63(30)$ \\
\hline Familial history & $4(12)$ & $13(28)$ & $10(10)$ & $30(17)$ & $33(16)$ \\
\hline Smokers & $18(53)$ & $31(67)$ & $51(50)$ & $86(49)$ & $100(48)$ \\
\hline Caucasian & $30(88)$ & $40(87)$ & $93(91)$ & $153(87)$ & $167(81)$ \\
\hline $\begin{array}{l}\text { North-African non-Jewish } \\
\text { ancestry }\end{array}$ & $2(6)$ & $6(13)$ & $8(8)$ & $16(9)$ & $26(13)$ \\
\hline Living outside Paris area & $13(38)$ & $19(41)$ & $26(25)$ & 57 (32) & $65(31)$ \\
\hline
\end{tabular}

Numbers in parentheses are percentages.

Intergroup comparisons showed no significant differences. 
Table 2 Cumulative characteristics of the five consecutive chronologic cohorts of patients seen in our unit within the three months following diagnosis (group 1)

\begin{tabular}{lccccc}
\hline & Cohort & Cohort & Cohort & Cohort & Cohort \\
& $1978-82$ & $1983-87$ & $1988-92$ & $1993-97$ & $1998-2003$ \\
\hline Patients (n) & 34 & 46 & 102 & 176 & 207 \\
Deceased & 4 & 2 & 3 & 3 & 0 \\
Lost to follow up & $14(41)$ & $20(43)$ & $42(41)$ & $70(40)$ & $24(12)$ \\
Median disease duration, months & $188(23-256)$ & $181(64-207)$ & $123(43-144)$ & $59(10-91)$ & $14(3-35)$ \\
(interquartile range) & & & & & \\
Vienna classification & $15(44)$ & $17(37)$ & $42(41)$ & $95(54)$ & $130(63)$ \\
Inflammatory & $9(26)$ & $4(9)$ & $17(17)$ & $22(13)$ & $11(5)$ \\
$\quad$ Stricturing & $10(29)$ & $25(54)$ & $43(42)$ & $59(34)$ & $66(32)$ \\
$\quad$ Penetrating & $6(18)$ & $7(15)$ & $20(20)$ & $57(32)$ & $60(29)$ \\
Medical treatment & $22(65)$ & $29(63)$ & $51(50)$ & $80(45)$ & $81(39)$ \\
$\quad$ No steroids, no IS & $6(18)$ & $10(22)$ & $31(30)$ & $39(22)$ & $66(32)$ \\
Steroids, no IS & 0 & $1(2)$ & $2(2)$ & $1(1)$ & $4(2)$ \\
IS & 0 & $1(2)$ & $1(1)$ & $7(4)$ & $13(6)$ \\
Early withdrawal of IS & & & & & \\
Infliximab & $18(53)$ & $23(50)$ & $53(52)$ & $120(68)$ & $161(78)$ \\
Cumulative number of intestinal & $11(32)$ & $17(37)$ & $42(41)$ & $50(28)$ & $45(22)$ \\
resections & $2(6)$ & $5(11)$ & $5(5)$ & $6(3)$ & 1 \\
$\quad 0$ & $3(9)$ & $1(2)$ & $2(2)$ & 0 & 0 \\
$\quad 1$ & & & & \\
2 & & & & \\
$>2$ & & & & & \\
\hline Numbers in parentheses are percentages. & & & & & \\
IS, immunosuppressants. & & & & & \\
\end{tabular}

of prescription of zero in the 1978-82 cohort to 0.56 (95\% CI 0.31 to 0.78 ) in the $1998-2002$ cohort.

\section{Cumulative need for excisional surgery in the five group 1 cohorts}

One hundred and ninety patients (34\%) were operated on at least once. Excisional surgery was performed in 41 cases before first admission in our unit and thereafter in 149 cases. Figure 2 gives the cumulative need for first excisional surgery. The curves were superimposed, with no significant difference from one curve to another ( $\log$ rank, $\mathrm{p}=0.81$ ). Excluding the 80 patients who had had surgery within the first three months following diagnosis yielded the same result ( $\log$ rank, $p=0.49$ ), although immunosuppressants were used in that group much earlier over the years (log rank, $\mathrm{p}<0.0001$ ). In the whole group of 565 patients, Cox analysis confirmed that the year of diagnosis had no significant effect upon the need for surgery. Factors associated with surgery were ileal involvement (HR 2.78; 95\% CI 2.19 to 3.51 ) and absence of rectal involvement (HR 0.34; 95\% CI 0.27 to 0.43 ). In the cohorts 1978-82, 1983-87, 1988-92, 1993-97, and 1998-2002, the five year cumulative probabilities of having a

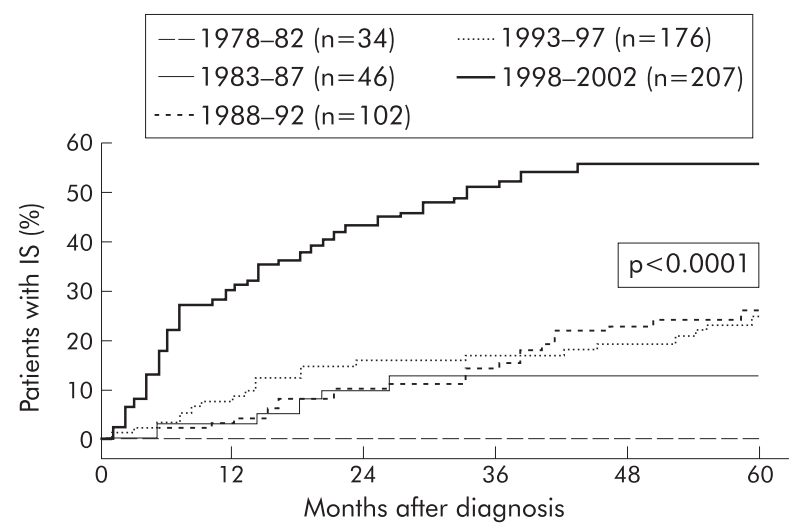

Figure 1 Kaplan-Meier estimates of the cumulative risk of receiving immunosuppressants in five chronologic cohorts of patients with Crohn's disease. large intestinal resection, defined by a post-surgical handicap index $\geqslant 20$, were $0.29(0.15-0.50), 0.20(0.10-0.36), 0.24$ $(0.16-0.35), 0.13(0.07-0.22)$, and $0.17(0.04-0.49)$, respectively. The curves were not significantly different according to $\log$ rank test $(p=0.23)$. The five year cumulative probability of having a definitive stoma varied not significantly between 0 and 0.03 from one cohort to another $(\mathrm{p}=0.33)$.

\section{Indications for first intestinal resection in group 1 patients}

Table 3 gives the indications for the first intestinal surgery in the five cohorts. The proportion of patients being operated on for medical failure, stricture, and perforation, respectively, did not change significantly between the five cohorts, although in the most recent cohort there was a clear reduction of operations for medical failure (13\% v 22-38\% in the other cohorts). Kaplan-Meier analysis of the cumulative probability of intestinal stricture and perforation did not show significant differences between cohorts. In the cohorts 1978-82, 1983-87, 1988-92, 1993-97, and 1998-2002, the five year cumulative probabilites of intestinal stricture were $0.23(0.11-0.43), 0.14 \quad(0.06-0.29), 0.19(0.12-0.30), 0.17$ $(0.11-0.26)$, and $0.10(0.02-0.42)$, respectively (log rank

Table 3 Indications for the first intestinal resection in the five consecutive chronologic cohorts of patients seen in our unit within the three months following diagnosis (group 1)

\begin{tabular}{lllll}
$\begin{array}{l}\text { Cohort } \\
1978-82\end{array}$ & $\begin{array}{l}\text { Cohort } \\
1983-87\end{array}$ & $\begin{array}{l}\text { Cohort } \\
1988-92\end{array}$ & $\begin{array}{l}\text { Cohort } \\
1993-97\end{array}$ & $\begin{array}{l}\text { Cohort } \\
1998-2002\end{array}$ \\
\hline 16 & 23 & 49 & 56 & 46 \\
$1(6)$ & 0 & 0 & $1(2)$ & $1(2)$ \\
$6(38)$ & $3(13)$ & $11(22)$ & $8(14)$ & $7(15)$ \\
$3(19)$ & $15(65)$ & $21(43)$ & $25(45)$ & $31(67)$ \\
$6(38)$ & $5(22)$ & $16(33)$ & $19(34)$ & $6(13)$ \\
& & & & \\
0 & 0 & 0 & $2(4)$ & $1(2)$ \\
0 & 0 & 1 & 1 & 0 \\
\hline
\end{tabular}

Numbers in parentheses are percentages.

*Other included mesenteric infarction, haematochezia, and small bowel adenocarcinoma, respectively. 


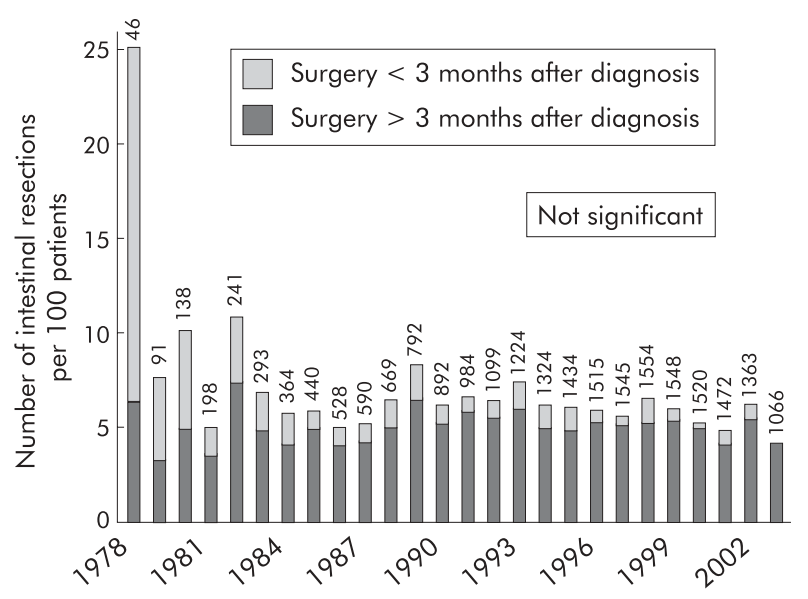

Figure 3 Evolution of the annual rate of intestinal resections from 1978-2003 in 2573 patients with Crohn's disease. The numbers above the columns indicate the number of patients at risk for intestinal resection at the beginning of the year.

$p=0.12$ ), and the five year cumulative probabilites of intestinal perforation were $0.03(0-0.19), 0.22(0.12-0.37)$, $0.18(0.11-0.29), 0.19(0.12-0.29)$, and $0.18(0.05-0.47)$, respectively $(\log$ rank $\mathrm{p}=0.22$ ). When analysing the time relation between prescription of immunosuppressants and first intestinal surgery, we found that in all the cohorts a great majority of patients were operated on without having received immunosuppressants, because surgery was performed early in the course of the disease (within the first three months following diagnosis $(\mathrm{n}=80,43 \%$ of operations)), or because surgery preceded or followed the prescription of immunosuppressants for less than three months $(n=92,49 \%)$. Only 16 patients $(9 \%)$ had to be operated on having received immunosuppressants for more than three months, and this proportion was not significantly different between cohorts $(0-17 \%)$.

\section{Referred patients (group 2)}

Of the 2008 patients referred to us more than three months after diagnosis, $880(44 \%)$ were operated on at least once. Excisional surgery was performed in 490 cases (56\%) before first admission in our unit and after in 390 cases. Thus compared with the first group of patients, a higher proportion of referred patients had had surgery before admission in our unit $(\mathrm{p}<0.001)$. Otherwise, results observed were similar to those of group 1 regarding an increased use of immunosuppressants but a stable need for excisional surgery over the years (table 4). The risk of having a definitive stoma remained also stable. However, in that group, the risk of having a large intestinal resection decreased significantly with time.

\section{Evolution of the need for surgery 1978-2003}

In the total cohort of 2573 patients from groups 1 and 2, 1070 underwent 1426 intestinal resections from January 1978 to December 2003 (22 928 patient years). Two hundred and seventeen resections (15\%) were performed within the first three months following diagnosis. Except for the year 1978 (46 patients only), the percentage of patients who were operated on during the first three months remained less than 5\% (fig 3). After the first three months, the operative rate (number of operations performed per year) fluctuated within a narrow range $(3.3-7.5 \%)$, without any significant change over 26 years (fig 3 ).

\section{DISCUSSION}

This study shows that although immunosuppressants were initiated much earlier during the course of CD, the need for intestinal resection remained stable over 25 years. The percentage of patients requiring intestinal surgery each year remained equal. The probability of having a definitive stoma appeared also to be unaffected from 1978 to 2002. However, large intestinal resections became more unusual.

This study has some limitations. Firstly, the retrospective nature of the study may have led to bias in the interpretation of the data-however, it was necessary to obtain an observation period long enough to ascertain the long term effect on surgery of changes in the medical strategy of CD. In addition, intestinal resection can be considered as an unbiased and solid criterion, even retrospectively, as it is performed only when necessary. Besides, during a period of 20-25 years, many factors other than the treatment strategy may have influenced the indications for surgery. However, all patients seen from the beginning were followed up in the same unit by the same small group of physicians, who used homogeneous guidelines and took collegial decisions. Moreover, comparison of cohorts at inclusion showed that

Table 4 Five year cumulative rates $(95 \% \mathrm{Cl})$ of therapeutic intervention in the patients referred to our unit more than three months after diagnosis of Crohn's disease (group 2, $\mathrm{n}=2008$ )

\begin{tabular}{|c|c|c|c|c|c|c|}
\hline & $\begin{array}{l}\text { Cohort } \\
1978-82\end{array}$ & $\begin{array}{l}\text { Cohort } \\
1983-87\end{array}$ & $\begin{array}{l}\text { Cohort } \\
\text { 1988-92 }\end{array}$ & $\begin{array}{l}\text { Cohort } \\
\text { 1993-97 }\end{array}$ & $\begin{array}{l}\text { Cohort } \\
1998-2002\end{array}$ & $\begin{array}{l}\text { Log rank } \\
\text { p value }\end{array}$ \\
\hline $\begin{array}{l}\text { Patients (n) } \\
\text { IS therapy }\end{array}$ & 218 & 342 & 486 & 563 & 399 & \\
\hline $\begin{array}{l}\text { Cumulative probability } \\
\text { (95\% Cl) }\end{array}$ & $\begin{array}{l}0.04 \\
(0.02-0.08)\end{array}$ & $\begin{array}{l}0.14 \\
(0.10-0.18)\end{array}$ & $\begin{array}{l}0.27 \\
(0.23-0.32)\end{array}$ & $\begin{array}{l}0.45 \\
(0.40-0.50)\end{array}$ & $\begin{array}{l}0.63 \\
(0.49-0.76)\end{array}$ & $<0.00001$ \\
\hline $\begin{array}{l}\text { Patients at risk ( } \mathrm{n} \text { ) } \\
\text { Intestinal resection }\end{array}$ & 195 & 278 & 296 & 203 & 17 & \\
\hline $\begin{array}{l}\text { Cumulative probability } \\
(95 \% \mathrm{Cl})\end{array}$ & $\begin{array}{l}0.36 \\
(0.29-0.48)\end{array}$ & $\begin{array}{l}0.30 \\
(0.25-0.35)\end{array}$ & $\begin{array}{l}0.32 \\
(0.28-0.37)\end{array}$ & $\begin{array}{l}0.31 \\
(0.27-0.36)\end{array}$ & $\begin{array}{l}0.36 \\
(0.22-0.53)\end{array}$ & 0.528 \\
\hline $\begin{array}{l}\text { Patients at risk (n) } \\
\text { Large intestinal resection }\end{array}$ & 137 & 227 & 274 & 263 & 21 & \\
\hline $\begin{array}{l}\text { Cumulative probability } \\
(95 \% \mathrm{CI})\end{array}$ & $\begin{array}{l}0.29 \\
(0.23-0.35)\end{array}$ & $\begin{array}{l}0.22 \\
(0.18-0.27)\end{array}$ & $\begin{array}{l}0.19 \\
(0.16-0.23)\end{array}$ & $\begin{array}{l}0.15 \\
(0.11-0.19)\end{array}$ & $\begin{array}{l}0.12 \\
(0.05-0.28)\end{array}$ & $<0.00001$ \\
\hline $\begin{array}{l}\text { Patients at risk ( } \mathrm{n} \text { ) } \\
\text { Definitive stoma }\end{array}$ & 145 & 250 & 321 & 310 & 27 & \\
\hline $\begin{array}{l}\text { Cumulative probability } \\
\text { (95\% CI) }\end{array}$ & $\begin{array}{l}0.01 \\
(0-0.03)\end{array}$ & $\begin{array}{l}0.02 \\
(0.01-0.04)\end{array}$ & $\begin{array}{l}0.02 \\
(0.01-0.04)\end{array}$ & $\begin{array}{l}0.02 \\
(0.01-0.04)\end{array}$ & $\begin{array}{l}0.02 \\
(0-0.13)\end{array}$ & 0.72 \\
\hline Patients at risk (n) & 202 & 315 & 387 & 355 & 33 & \\
\hline
\end{tabular}


they were very similar regarding demographic characteristics and disease location. In particular there is no reason to believe that $\mathrm{CD}$ became more severe with time while other disease characteristics did not change. Secondly, it should be noted that a relatively large proportion of patients were lost to follow up. We made no attempt to contact the patients or physicians to update the data. We do not believe this may have minimised the need for surgery of the oldest cohorts because patients who are lost to follow up are usually those doing well and not requiring further surgery. The cumulative probability of surgery in our patients was very similar to those reported in two unbiased and complete series of the literature, the NCCDS ${ }^{17}$ and the Copenhagen County cohort study. ${ }^{18}$ Finally, our unit is a tertiary referral centre and referral bias is unavoidable. To limit this bias, we restricted the analysis to patients seen during the first three months of the disease course. This precaution was not sufficient to eliminate such a referral bias because an important proportion of these patients came to surgery during that period. However, when we excluded these latter patients, analyses gave similar results and, in particular, the discrepancy between an increased use of immunosuppressants and a stable need for surgery remained unchanged. These results were confirmed in a second large group of patients.

The occurrence of stricturing and perforating complications was the main reason for excisional surgery. The frequency of these complications did not change significantly from one cohort to another. This is a disappointing result because it could be expected that immunosuppressants could have an anatomic effect and prevent these complications. Indeed, $\mathrm{D}^{\prime}$ Haens et al reported that in $74 \%$ of patients with colonic or ileocolonic disease who were clinically responders to azathioprine, endoscopic lesions had healed completely or nearly completely after a mean of two years of treatment. Histologically there was disappearance of the inflammatory infiltrate, with only a degree of architectural disturbance remaining. ${ }^{19}$ In the present study there was, over the most recent years, a clear decrease of intestinal resection for medical failure, which represented only 13\% of surgical indications in the 1998-2002 cohort. This result may be related to immunosuppressants, but also to infliximab even though it was used sparingly in very few patients. In any case, the absence of a decrease in the need for surgery over the last 25 years questions the efficiency of our medical strategy. In fact, there is the possibility that in this study immunosuppressants had no impact on complications and the need for surgery because they were given too late during the course of the disease. Supporting this hypothesis, a large majority of patients came to surgery while not having received immunosuppressants, or were operated on early (within the first three months), while the mean time of response to purine analogues is three months. ${ }^{20}$ By contrast, if we make the hypothesis that immunosuppressants are able to change the natural history of $C D$, nearly half the patients who were operated on more than three months after diagnosis could have avoided surgery. Thus we can extrapolate that in our series immunosuppressants were given too late and too scarcely to have a significant impact on the need for surgery. Such an assertion is not in accordance with the anatomic effect observed by D'Haens et al, ${ }^{19}$ that immunosuppressants, even when given early, may have no preventive effect on the occurrence of stricturing and penetrating complications.

An interesting and more encouraging result of our study was the decrease of the probability of having a large intestinal resection over the last 25 years in the group of referred patients. A similar trend, although not significant, was observed in patients who were seen early after diagnosis and were, for the most part, operated on in our surgical unit. The reason for such a decrease, from $29 \%$ to $12 \%$ five years after diagnosis, may be linked to a greater use of immunosuppressants, but may also be a change in the surgical strategy favouring segmental and limited resections in the most recent years.

In summary, this study shows that immunosuppressants have been used increasingly over the years. However, this evolving therapeutic strategy was not associated with a decrease in the need for surgery or in a decrease of the occurrence of intestinal complications. This result does not question the efficacy of immunosuppressants for achieving and maintaining remission, ${ }^{21}$ sparing steroids, ${ }^{22}$ and improving quality of life, but it does questions the timing of starting immunosuppressants in patients with moderate to severe Crohn's disease.

\section{Authors' affiliations}

J Cosnes, I Nion-Larmurier, L Beaugerie, P Afchain, J-P Gendre, Service de Gastroentérologie et Nutrition, Hôpital Saint-Antoine, Paris, France

E Tiret, Service de Chirurgie, Hôpital Saint-Antoine, Paris, France

\section{REFERENCES}

1 Hanauer SB, Dassopoulos T. Evolving treatment strategies for inflammatory bowel disease. Annu Rev Med 2001;52:299-318.

2 Lennard-Jones JE. Azathioprine in the treatment of Crohn's disease. Proc R Soc Med 1972;65:291-3

3 Feagan BG. Standard immunosuppression in IBD: current practice. Acta Gastroenterol Belg 2001;64:182-8.

4 Korelitz BI, Present DH. A history of immunosuppressive drugs in the treatment of inflammatory bowel disease: origins at the Mount Sinai Hospital. Mt Sinai J Med 1996;63:191-201.

5 Pearson DC, May GR, Fick GH, et al. Azathioprine and 6-mercaptopurine in Crohn disease. A meta-analysis. Ann Intern Med 1995; 123:132-42.

6 Lewis JD, Schwartz JS, Lichtenstein GR. Azathioprine for maintenance of remission in Crohn's disease: benefits outweigh the risk of lymphoma. Gastroenterology 2000;118:1018-24.

7 Hanauer SB. Crohn's disease: step up or top down therapy. Best Pract Res Clin Gastroenterol 2003;17:131-7.

8 Markowitz J, Grancher K, Kohn N, et al. A multicenter trial of 6mercaptopurine and prednisone in children with newly diagnosed Crohn's disease. Gastroenterology 2000;1 19:895-902.

9 Targan SR, Hanauer SB, van Deventer SJ, et al. A short-term study of chimeric monoclonal antibody CA2 to tumor necrosis factor alpha for Crohn's disease. Crohn's Disease cA2 Study Group. N Engl J Med 1997;337:1029-35.

10 Hanaver SB, Feagan BG, Lichtenstein GR, et al. Maintenance infliximab for Crohn's disease: the ACCENT I randomised trial. Lancet 2002;359:1541-9.

11 Sands BE, Anderson FH, Bernstein CN, et al. Infliximab maintenance therapy for fistulizing Crohn's disease. N Engl J Med 2004;350:876-85.

12 Lennard-Jones JE. Classification of IBD. Scand J Gastroenterol 1989;170:2-4.

13 Cosnes J, de Parades V, Carbonnel F, et al. Classification of the sequelae of bowel resection for Crohn's disease. Br J Surg 1994;81:1627-31.

14 Gasche C, Scholmerich J, Brynskov J, et al. A simple classification of Crohn's disease: report of the Working Party for the World Congresses of Gastroenterology, Vienna 1998. Inflamm Bowel Dis 2000;6:8-15.

15 Cosnes J, Carbonnel F, Beaugerie L, et al. Effects of cigarette smoking on the long-term course of Crohn's disease. Gastroenterology 1996;1 10:424-31.

16 Cosnes J CS, Blain A, Beaugerie L, et al. Long-term evolution of disease behavior of Crohn's disease. Inflamm Bowel Dis 2002;8:244-50.

17 Mekhiian HS, Switz DM, Melnyk CS, et al. Clinical features and natural history of Crohn's disease. Gastroenterology 1979;77:898-906.

18 Munkholm P, Langholz E, Davidsen M, et al. Disease activity courses in a regional cohort of Crohn's disease patients. Scand J Gastroenterol 1995; 30:699-706.

19 D'Haens G, Geboes K, Rutgeerts P. Endoscopic and histologic healing of Crohn's (ileo-) colitis with azathioprine. Gastrointest Endosc 1999;50:667-71

20 Present DH, Korelitz BI, Wisch N, et al. Treatment of Crohn's disease with 6mercaptopurine. A long-term, randomized, double-blind study. N Engl J Med 1980;302:981-7.

21 Pearson DC, May GR, Fick G, et al. Azathioprine for maintaining remission of Crohn's disease. Cochrane Database Syst Rev 2000:CD000067.

22 Present DH. 6-Mercaptopurine and other immunosuppressive agents in the treatment of Crohn's disease and ulcerative colitis. Gastroenterol Clin North Am 1989;18:57-71. 


\section{LETTERS}

\section{Efficacy and strategy of pneumatic dilatation in achalasia}

We read with interest the article by Eckardt et al regarding the long term results of pneumatic dilatation in achalasia (Gut 2004;53:629-33). Fifty four patients were followed up for a median of 14 years after a single pneumatic dilatation using the Browne-McHardy dilator. Five and 10 year remission rates were $40 \%$ and $36 \%$, respectively, and repeated dilatations only mildly improved the clinical response. Most of the relapses occurred within one year of dilatation. Patients with post-dilatation lower oesophageal sphincter pressures of $<10 \mathrm{~mm} \mathrm{Hg}$ had a significantly better outcome. The authors suggest that failure to respond to the first dilatation should lead to consideration of alternative therapy.

We disagree with this conclusion and we would like to bring to your attention a recent prospective study on the long term effects of pneumatic dilatation in 11 patients with achalasia. ${ }^{1}$ A different approach was chosen-that is, treatment consisted of one or more pneumatic dilatations under conscious sedation in order to achieve stable clinical remission, defined as persisting one year after dilatation. To this end, closer follow up was performed in the first year after dilatation (scheduled assessments at three and 12 months). Thereafter, clinical and manometric assessments were performed yearly for six years. The clinical score was according to Eckardt et al. Five patients needed one $(30 \mathrm{~mm}$ diameter Rigiflex dilator) and six needed two (30 and $35 \mathrm{~mm}$ diameter) dilatations. No complications occurred. All patients remained in clinical remission and their lower oesophageal sphincter pressure decreased to $<10 \mathrm{~mm} \mathrm{Hg}$ and remained unchanged over time.

There are similarities in the results of the two studies: (1) the outcome of our 11 patients was comparable with that of the eight patients of Eckardt et al with a lower oesophageal sphincter pressure of $<10 \mathrm{~mm} \mathrm{Hg}$ who had a remission rate of $75 \%$ at six years; and (2) the observation that the six patients in our series who needed a second dilatation all relapsed within one year of the first dilatation agrees with the data by Eckardt et al, showing that most relapses occur in the first 12 months. However, our dilatations were more successful and, importantly, a second dilatation led to a sustained remission in all patients. We do not know the reasons for this difference but we believe it may be at least partly related to our use of the non-compliant Rigiflex dilator, which is currently considered the best choice, although there are no adequately powered comparisons with the Browne-McHardy dilator in the literature. ${ }^{3}$ Similarly to our result, a recent paper has shown very good efficacy of a second dilatation with the Rigiflex dilator in patients who had relapsed. ${ }^{4}$ Another possible reason is the use of conscious sedation during the procedure which allowed us to complete all dilatations; Eckardt et al, who used topical anaesthesia only, had to prematurely terminate $17 \%$ of the procedures.

In conclusion, our published experience and our current clinical practice, involving treatment and follow up of 10-15 new achalasia patients each year, suggest that performance of one or two dilatations until stable clinical remission is a valuable strategy, and that pneumatic dilatation under conscious sedation with the Rigiflex dilator is an effective long term treatment in most patients with achalasia.

R Penagini, P Cantù Cattedra di Gastroenterologia, Dipartimento di Scienze Mediche, University of Milan, IRCCS Ospedale Maggiore, Milan, Italy

Correspondence to: Professor R Penagini, Cattedra di Gastroenterologia, Dipartimento di Scienze Mediche, University of Milan, IRCCS Ospedale Maggiore, Milan, Italy; roberto.penagini@unimi.it

Conflict of interest: None declared.

\section{References}

1 Penagini $R$, Cantù $P$, Mangano $M$, et al. Longterm effects of pneumatic dilatation on symptoms and lower oesophageal sphincter pressure in achalasia. Scand I Gastroenterol 2002;37:380-4.

2 Vaezi MF, Richter JE. Current therapies for achalasia: comparison and efficacy. J Clin Gastroenterol 1998:27:21-35.

3 Stark GA, Castell DO, Richter JE, et al Prospective randomized comparison of BrownMcHardy and Microvasive balloon dilators in treatment of achalasia. Am J Gastroenterol 1990:85:1322-6.

4 Mikaeli J, Bishehsari F, Montazeri G, et al. Pneumatic balloon dilatation in achalasia: a prospective comparison of safety and efficacy with different balloon diameters. Aliment Pharmacol Ther 2004;20:431-6.

\section{Authors' reply}

Penagini and Cantù should be congratulated for the remarkable results they were able to obtain in 11 patients with achalasia treated by pneumatic dilation. To my knowledge, not a single study has so far produced similar results. A review of prospective studies in patients undergoing pneumatic dilation with the Rigiflex dilator ${ }^{1}$ indicated that approximately $80 \%$ will have a good or excellent short term response. However, if such patients are observed for prolonged periods, the results obtained do not differ significantly from those observed following treatment with the older balloons. In a recent study, in which 56 patients were treated with the Rigiflex dilator and observed for more than 10 years, the long term success rate was $55 \%{ }^{2}$ Thus it is my impression that differences in treatment results are not so much related to differences in technique and operator experience but rather to the number of patients investigated, duration of follow up, and finally the quality of the study design. It is hoped that carefully designed randomised studies, which are now in progress, will tell us whether we should continue to offer pneumatic dilation to the great majority of patients with achalasia or whether we should advise them to undergo surgery instead.
V F Eckardt

Correspondence to: Dr V F Eckardt, Deutsche Klinik für Diagnostik, Aukammallee 33 Wiesbaden 65191, Germany; eckardt.gastro@dkd-wiesbaden.de

Conflict of interest: None declared.

\section{References}

1 Kadakia SC, Wong RKH. Pneumatic balloon dilation for esophageal achalasia. Gastrointest Endosc Clin N Am 2001;11:325-45.

2 West RL, Hirsch DP, Bartelsman JFWM, et al. Long term results of pneumatic dilation in achalasia followed for more than 5 years. Am J Gastroenterol 2002;97:1346-51.

\section{Probiotics in IBD: mucosal and systemic routes of administration may promote similar effects}

We read with considerable interest the paper by Sheil et al (Gut 2004;53:694-700) who reported the successful application of the subcutaneous route for probiotic attenuation of colitis.

We agree with the corresponding commentary of Ghosh et al (Gut 2004;53:620-2) regarding the need to study mechanisms underlying probiotic interactions. Recently, we further standardised a method to compare the anti-inflammatory potential of orally administered lactic acid bacteria (LAB) in a murine model of acute 2,4,6, trinitrobenzene sulphonic acid (TNBS) induced colitis. ${ }^{1}$ This model allowed us to discriminate "protective" strains, showing between $30 \%$ and $70 \%$ reduction of inflammatory score, from strains which did not significantly attenuate experimental colitis. We could select highly performing strains of Lactobacillus salivarius and Lactobacillus rhamnosus that consistently lowered colitis. In comparison, a strain of Lactobacillus acidophilus, Lactococcus lactis, and Streptococcus gordonii never showed any improvement. For all five strains, we investigated the protective effect of a single intraperitoneal injection of $5 \times 10^{7}$ live microorganisms, 24 hours prior to induction of colitis. Surprisingly, protection by the LAB strains via this systemic route closely matched the efficiency of the oral route (fig 1).

When evaluating both routes simultaneously, the anti-inflammatory effect was of comparable magnitude. Moreover, the prophylactic impact of the intraperitoneal Lactobacillus salivarius strain was established up to two hours before TNBS administration. It is noteworthy that two delayed injections could lead to protection but caused marked weight loss $(23 \%(\mathrm{p}<0.05) \vee 15 \%$ and $11 \%$, respectively, for control and oral route groups) with alleged fever.

Our findings clearly confirm those of Sheil et al (Gut 2004;53:694-700) showing strain specific in vivo probiotic effects distant from the target tissue, suggesting a relationship between the type of LAB (or LAB components) and peritoneal immunocompetent cells. Pereyra and colleagues ${ }^{2}$ reported transient dose dependant induction of a/b-like interferon in serum of intraperitoneal injected Lactobacillus bulgaricus while Streptococcus thermophilus did not. Recent 


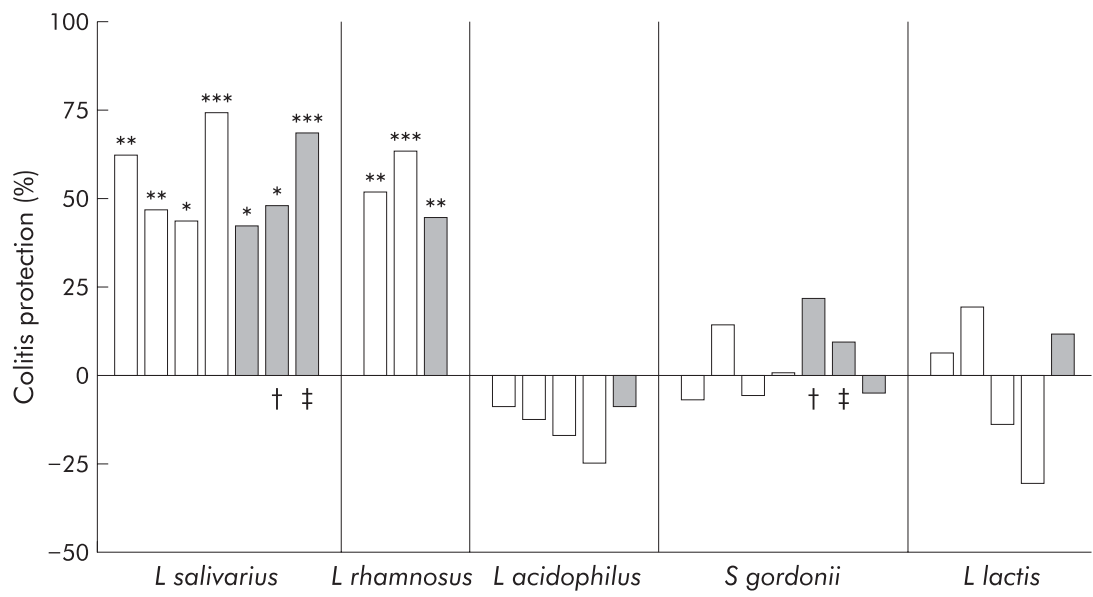

$\square$ Oral route: $1 \times 10^{8} \mathrm{cfu} / \mathrm{d}-5$ consecutive days prior to TNBS

$\square$ Intraperitoneal route: $5 \times 10^{7} \mathrm{cfu}-1$ day prior to TNBS

$+1 \times 10^{8} \mathrm{cfu}-2 \mathrm{~h}$ prior to TNBS

$\ddagger 5 \times 10^{7} \mathrm{cfu} / \mathrm{d}-6$ and 1 day prior to TNBS

Figure 1 Lactic acid bacteria (LAB) protection on macroscopic damages induced by $2,4,6$, trinitrobenzene sulphonic acid (TNBS): the impact of the oral or intraperitoneal route of $L A B$ administration on reduction of TNBS induced colitis in mice. Results are expressed as per cent reduction of mean macroscopic inflammation ${ }^{7}$ of mice treated with $L A B$, in relation to the mean score of non-treated mice. Colitis index was assessed 48 hours after TNBS administration. Each bar represents an independent experiment of control $(n=10)$ and LAB treated mice $(n=10)$. ${ }^{*} p<0.05$, ${ }^{* *} p<0.01,{ }^{* * *} p<0.001$, significantly different from the corresponding TNBS control group (MannWhitney Ú test). CFU, colony forming unit; d; day.

observations showed that heat treatment of an orally administered probiotic cocktail abolished the colitis protection in a DSS model, while irradiation improved it. Consequently, cellular integrity appears to be necessary to explain at least some part of the effect, although cell walls and peptidoglycans of killed bacteria cannot be considered as passive. Possibly both "good" and "bad" signals are given out by LAB, and the immune system is integrating all of them. Those "mixed" signals will no doubt be specific for each strain as well as dose dependent. Differences in physicochemical status could explain the mortality seen by Sheil et al, especially when using heat treated bacteria. Pereyra and colleagues ${ }^{2}$ established that the maximal non-lethal quantity of injected live LAB was $5 \times 10^{7}$ but it can be hypothesised that toxicity may also differ with strain and viability status. Both pro- and anti-inflammatory components of probiotics have been reported to interact with systemic immune cells, showing effects comparable with other well known anti-inflammatory or therapeutic molecules. ${ }^{4}$ It is therefore most probable that systemic delivery of specific live or killed probiotics may influence the delicate balance between Th1 and Th2 immunity, and subsequently have an impact on local immunity. Clear relationships, however, are not obvious. A first example is the case of subcutaneous CpG DNA that promoted a Thl response and was able to alleviate some symptoms of DSS colitis but caused inflammation when administered after the onset of colitis. ${ }^{5}$ Secondly, different experimental models of colitis support a potential benefit of probiotic DNA, ${ }^{3}$ although it seems very premature to restrict this probiotic effect to nucleic acids only. ${ }^{6}$

As emphasised by Gosh and colleagues (Gut 2004;53:620-2), approaches involving fractional studies are essential tools to complete the knowledge obtained from in vitro and ex vivo models and assist in understanding the interactions between LAB and the immune system. These studies may reveal common mechanisms active in inflammation, tolerance, and allergy models. Even if this study confirms the importance of the systemic route for certain probiotic activity, we cannot neglect the possible influence of local and innate immunity, the general status of the gut flora, and the role of epithelial cells in the cross talk between both.

\section{Acknowledgements}

We are indebted to Danisco France for financial support.

B Foligné, C Grangette, B Pot

Bactériologie des Ecosystèmes, Institut Pasteur de Lille, Lille, France

Correspondence to: $\mathrm{Dr}$ B Pot, Institut Pasteur de Lille,

1 Rue du Prof Calmette, BP 245, F-59019 Lille,

France; bruno.pot@ibl.fr

Conflict of interest: None declared.

\section{References}

1 Foligné B, Nutten S, Steidler L, et al. Potentialities of the TNBS-induced colitis model to evaluate the anti-inflammatory properties of lactic acid bacteria. Dig Dis (in press).

2 Pereyra BS, Falcoff R, Falcoff E, et al. Interferon induction by Lactobacillus bulgaricus and Streptococcus thermophilus in mice. Eur Cytokine Netw 1991;2:299-303.

3 Rachmilewitz D, Katakura K, Karmeli F, et al. Tolllike receptor 9 signaling mediates the antiinflammatory effects of probiotics in murine experimental colitis. Gastroenterology 2004; 126:520-8.

4 Mercenier A, Pavan S, Pot B. Probiotics as biotherapeutic agents: present knowledge and future prospects. Curr Pharm Des 2003;9:175-9.
5 Obermeier F, Dunger N, Strauch UG, et al Contrasting activity of cytosin-guanosin dinucleotide oligonucleotides in mice with experimental colitis. Clin Exp Immunol 2003;134:217-24.

6 Reid G, Guarner F, Gibson G, et al. Discussion on toll-like receptor 9 signaling mediates the antiinflammatory effects of probiotics in murine experimental colitis. Gastroenterology 2004; 127:366-7.

7 Wallace JL, MacNaughton WK, Morris GP, et al. Inhibition of leukotriene synthesis markedly accelerates healing in a rat model of inflammatory bowel disease. Gastroenterology 1989;96:29-36.

\section{Mutations in anionic trypsinogen gene are not associated with tropical calcific pancreatitis}

Pancreatitis is considered to be an autodigestive disease due to premature activation of trypsinogen inside the pancreas. Its genetic basis has recently been established with the identification of causal mutations in cationic trypsinogen gene (PRSSI) in patients with hereditary $^{1}$ and non-hereditary pancreatitis. ${ }^{2}$ Mutations in other genes such as SPINKI (encoding pancreatic secretory trypsin inhibitor $)^{3}$ and cystic fibrosis transmembrane conductance regulator $(C F T R)^{45}$ genes have also been associated with the disease. Tropical calcific pancreatitis is a type of idiopathic pancreatitis, reported particularly in the tropics. Recently, we and others demonstrated absence of PRSS1 mutations but significant prevalence of the N34S mutation in the SPINK1 gene in these patients. ${ }^{6-8}$ However, our study raised two important questions: firstly, the exact role of SPINKI mutations in disease causation as cationic trypsinogen is normal with an intact autolysis site; and secondly, the cause of the disease in the remaining patients negative for both PRSSI and SPINKI mutations.

Of the nine members of the human trypsinogen gene family, only PRSS1, PRSS2, and PRSS3 are functional genes coding for cationic, anionic, and meso-trypsinogen isoforms, respectively. The anionic form accounts for about one third of the total trypsins in pancreatic juice. We investigated whether mutations in the anionic trypsinogen gene may contribute to the pathogenesis of tropical calcific pancreatitis. Of 20 mutations reported to date in the PRSSI gene, 17 are clustered in exons 2 and 3 only. The remaining three are in the promoter region but reported in isolated patients. Hence we initially screened exons 2 and 3 of the anionic trypsinogen gene in 68 well characterised Indian patients with tropical calcific pancreatitis. ${ }^{6}$ Subsequently, we also sequenced the promoter, complete coding region, and the flanking region in an attempt to look for any novel mutation.

Owing to the extremely high sequence homology between PRSSI and PRSS2, a nested polymerase chain reaction (PCR) was used to ensure specificity. The primers were selected from the published study of Chen and colleagues ${ }^{9}$ and all of the exons of PRSS 2 were PCR amplified, purified, and sequenced on both alleles using internal sequencing primers and the Big Dye terminator cycle sequencing approach. However, we did not find any of the reported or any novel mutations in the coding region or in the splice site junctions, except a synonymous polymorphism A90A (GCA>GCG) in exon 3 of the anionic trypsinogen gene. This variation was observed in both the heterozygous 
and homozygous states with a mutant allele frequency of 0.58 (9 AA, $20 \mathrm{GG}$, and $39 \mathrm{AG}$ ) and was comparable with 0.61 in 50 controls (7 AA, $18 \mathrm{GG}$ and $25 \mathrm{AG}$ ) analysed.

Our results thus exclude any association of mutations in the anionic trypsinogen gene in tropical calcific pancreatitis and suggest a role for other genetic or non-genetic factors in the pathogenesis of the disease. Screening of genes such as CFTR may explain the disease in the remaining patients. It also affirms the importance of the N34S mutation in SPINKI as the major genetic factor for this type of pancreatitis.

M M Idris*, S Bhaskar* Centre for Cellular and Molecular Biology, Hyderabad, India

D N Reddy

Asian Institute of Gastroenterology, Hyderabad, India

K R Mani

Centre for Cellular and Molecular Biology, Hyderabad, India

G V Rao

Asian Institute of Gastroenterology, Hyderabad, India

L Singh, G R Chandak

Centre for Cellular and Molecular Biology,

Hyderabad, India

Correspondence to: $\operatorname{Dr}$ G R Chandak, Centre for Cellular and Molecular Biology, Uppal Rd Hyderabad, AP 500 007, India chandakgrc@ccmb.res.in

doi: 10.1136/gut.2004.055335

${ }^{*} \mathrm{MM}$ Idris and S Bhaskar contributed equally to this work.

Conflict of interest: None declared.

\section{References}

1 Whitcomb DC, Gorry MV, Preston RA, et al. Hereditary pancreatitis caused by a mutation in the cationic trypsinogen gene. Nat Genet 1996; 14:141-5

2 Gorry MC, Gabbaizedeh D, Furey W, et al. Mutations in the cationic trypsinogen gene are associated with recurrent acute and chronic pancreatitis. Gastroenterology 1997; 113:1063-8.

3 Witt $\mathrm{H}$, Luck W, Hennies $\mathrm{HC}$, et al. Mutations in the gene encoding the serine protease inhibitor Kazal type I are associated with chronic pancreatitis. Nat Genet 2000;25:213-16.

4 Sharer N, Schwarz M, Malone G, et al. Mutations in the cystic fibrosis gene in patients with chronic pancreatitis. N Engl J Med 1998;339:645-52.

5 Cohn JA, Friedman KJ, Noone PG, et al. Relation between mutations of the cystic fibrosis gene and idiopathic pancreatitis. $N$ Engl J Med 1998;339:653-8.

6 Chandak GR, Idris MM, Reddy DN, et al. Mutations in the pancreatic secretory trypsin inhibitor gene (PSTI/SPINK1) rather than the cationic trypsinogen gene (PRSS1) are significantly associated with tropical calcific pancreatitis. J Med Genet 2002;39:347-51

7 Bhatia E, Chowdhuri G, Sikora SS, et al. Tropical calcific pancreatitis: strong association with SPINK 1 trypsin inhibitor mutations. Gastroenterology 2002;123:1020-5.

8 Schneider A, Suman A, Rossi L, et al. SPINK1/ PSTI mutations are associated with tropical pancreatitis and type II diabetes mellitus in Bangladesh. Gastroenterology 2002; 123:1026-30.

9 Chen J, Audrezet M, Mercier B, et al. Exclusion of anionic trypsinogen and mesotrypsinogen involvement in hereditary pancreatitis without cationic trypsinogen gene mutations. Scand J Gastroenterol 1999;8:831-2.
Elevated plasma protein C levels correlate with the presence of fatty liver (NASH and NAFLD)

The clinical implications of non-alcoholic fatty liver disease (NAFLD) are derived mostly from its common occurrence in the general population and the potential of the condition to progress to fibrosis and cirrhosis. ${ }^{1}$ Markers that help in making an early diagnosis and treatment are warranted. Protein $\mathrm{C}$ is a vitamin $\mathrm{K}$ dependent glycoprotein that functions as a circulating anticoagulant through proteolytic cleavage and inactivation of the coagulation factors Va and VIIIa. ${ }^{2}$ Whether or not protein C levels increase in patients with NAFLDs has not been assessed.

We measured protein $C$ levels in 44 patients (28 men and 16 women; mean ages 45 (11) and 49 (12) years, respectively); 15 patients with fatty liver (FL), 15 with nonalcoholic steatohepatitis (NASH), and 14 with chronic viral hepatitis $\mathrm{B}+\mathrm{C}(\mathrm{CH})$. All were diagnosed by histology and liver technetium scan or ultrasound. Ten healthy subjects were used as controls. Obesity, hyperlipidaemia, and diabetes were present in $60 \%, 73 \%$, and $23 \%$ of cases, respectively; $64 \%$ of patients had elevated liver enzyme tests (alanine aminotransferase 45 (21) IU/l in FL and 43 (18) IU/l in NASH). Mean protein $\mathrm{C}$ levels were significantly increased in patients with NAFLD $(\mathrm{n}=30)$ compared with those with chronic viral hepatitis ( 140 $(36) \%$ v $101(24) \% ; \mathrm{p}<0.0009)$ and healthy individuals ( $140(36) \% v 120(12) ; \mathrm{p}<0.04)$. No significant difference in protein $\mathrm{C}$ levels was noted between simple fatty liver and NASH. (149 (34)\% and 130 (37)\%, respectively; $\mathrm{p}=0.07))$. A significant correlation was found between protein $\mathrm{C}$ and extent of fatty infiltration $(r=0.63 ; \mathrm{p}<0.001)$ (fig 1$)$, insulin resistance index $(r=0.3 ; \mathrm{p}<0.01)$, and triglyceride levels $(r=0.45, \mathrm{p}<0.001)$. Protein C could discriminate correctly between NAFLDs and chronic viral hepatitis in $82 \%$ of cases. No significant association was found between protein $\mathrm{C}$ and aminotransferase levels.

In conclusion, protein $\mathrm{C}$ was elevated in patients with NAFLD. The underlying mechanism remains unknown. Agewall et al suggested an increase in hepatic synthesis of protein $\mathrm{C}$ due to increased hepatic insulin resistance. $^{3} \quad$ Increased levels have been

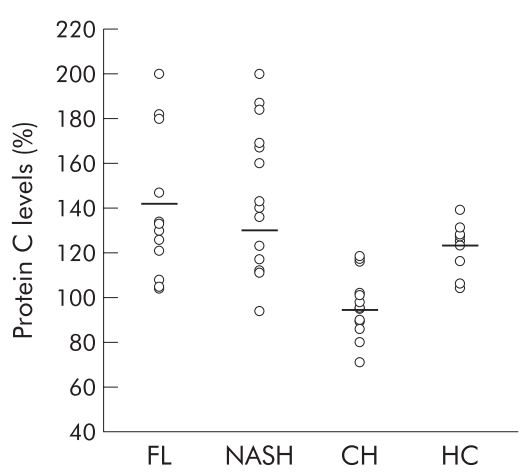

Figure 1 Protein C levels (normal 70-130\%) in the study population (fatty liver (FL), nonalcoholic steatohepatitis (NASH), chronic viral hepatitis $\mathrm{B}+\mathrm{C}(\mathrm{CH})$, and healthy controls $(\mathrm{HC})$ ). Horizontal bars indicate median levels. reported in patients with diabetes, hypertriglyceridaemia, and nephrotic syndrome, with the use of anabolic steroids, oral contraceptives, and alcohol, and with increasing age. ${ }^{4}$ Diabetes and hypertriglyceridaemia are predisposing conditions to fatty liver ${ }^{5}$ and were present in $23 \%$ and $73 \%$ of cases, respectively. The remaining conditions were excluded by clinical and biochemical findings. Although more studies are needed, these preliminary findings suggest that elevated protein $\mathrm{C}$ levels together with elevated liver enzymes may be used as markers for NAFLD and may obviate the need for liver biopsy.

N Assy

Department of Internal Medicine A, and Liver Unit, Sieff Government Hospital, Safed, Israel, and Technion Institute, Faculty of Medicine, Haifa, Israel

S Schlesinger Department of Internal Medicine A, Sieff Government Hospital, Safed, Israel

O Hussein Department of Internal Medicine A, Sieff Government Hospital, Safed, Israel, and Technion Institute, Faculty of Medicine, Haifa, Israel

Correspondence to: Dr N Assy, Liver Unit, Sieff Government Hospital, Safed 13100, Israel assy.n@ziv.health.gov.il

doi: 10.1136/gut.2004.060251

Conflict of interest: None declared.

\section{References}

1 Angulo P. Nonalcoholic fatty liver disease. N Engl J Med 2002;346:1221-31.

2 Bajzar L. Thrombin activatable fibrinolysis inhibitor and an antifibrinolytic pathway. Arterioscler Thromb Vasc Biol 2000;20:251 1-18.

3 Agewall S, Bokemarket L, Wiskstrand J, et al. Insulin sensitivity and haemostatic factors in clinically healthy 58-year old men. Thromb Haemost 2000;84:571-5.

4 Bell H, Odegaard OR, Anderson T, et al. Protein $\mathrm{C}$ in patients with alcoholic cirrhosis and other liver diseases. J Hepatol 1992;14:163-7.

5 Assy N, Kaita K, Mymin D, et al. Fatty infiltration of liver in hyperlipidemic patients. Dig Dis $\mathrm{Sci}$ 2000;45:1929-34

\section{Coexistent chronic idiopathic intestinal pseudo obstruction and inflammatory bowel disease}

Chronic idiopathic intestinal pseudo obstruction (CIIP) is a severe condition presenting with abdominal pain and dysmotility. Inflammatory or degenerative changes of the autonomic nervous system or of the muscles of the bowel have been observed in CIIP. ${ }^{12}$ As patients with inflammatory bowel disease (IBD) may show clinical ${ }^{34}$ and histological ${ }^{5}$ signs of autonomic neuropathy and dysmotility, ${ }^{67}$ the aim of this study was to examine whether there is an association between CIIP and IBD.

Six patients at our hospital presenting with signs and symptoms of intestinal dysmotility were diagnosed with CIIP based on clinical features, antroduodenojejunal manometry, and full thickness biopsies (table 1). ${ }^{89}$ Patient No 1 had an acute erosive colitis some years previously with bloody diarrhoea and an enhanced sedimentation rate, which was treated with steroids, and patient No 2 had relapsing proctitis treated with 5 -aminosalicylic acid (5-ASA). Patient No 3 was 
Table 1 Summary of the findings in our patients

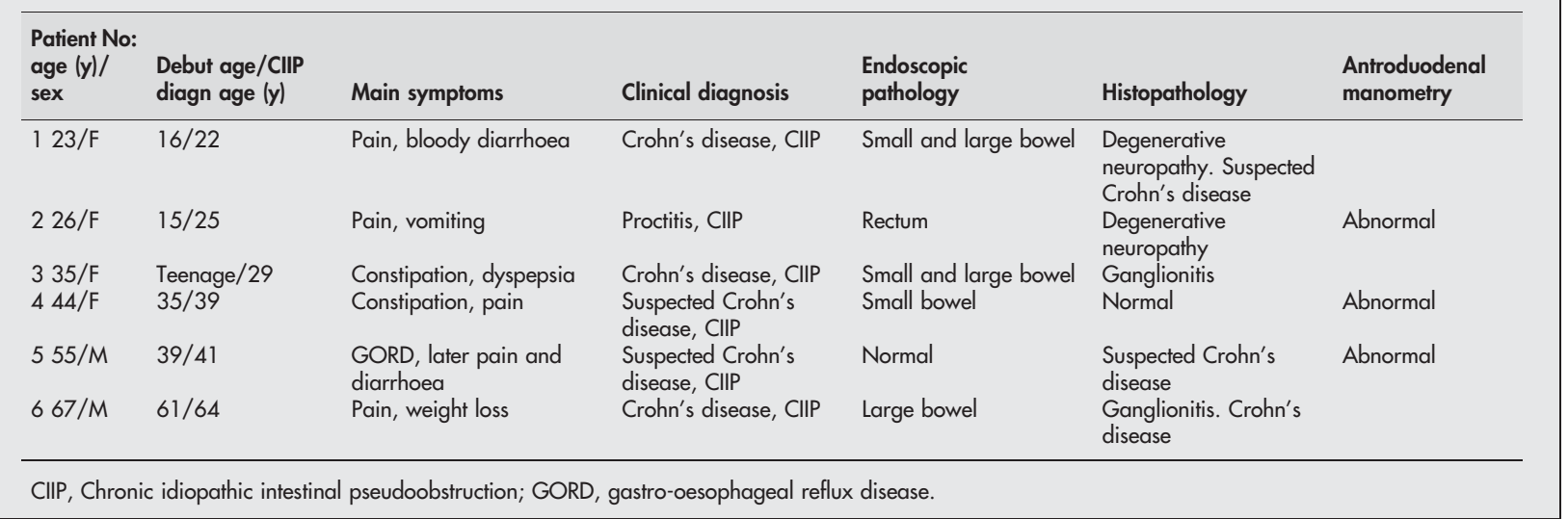

totally and patient No 4 partially colectomised because of slow transit constipation. Patient No 6 was proctocolectomised due to refractory colitis. The patients were further investigated with magnetic resonance (MR) enterography ${ }^{10}$ and video capsule enteroscopy to establish whether there were any signs of IBD. If these examinations showed any pathology, push enteroscopy and ileocolonoscopy were also performed. All biopsies collected over the years were re-evaluated.

MR enterography did not reveal any pathological changes in any of the subjects. In three patients (Nos 1, 3, and 4), video capsule enteroscopy revealed Crohn-like ulcerations/erosions in the stomach and small intestine. Further examination of patient No 1 by push enteroscopy confirmed the erosions in the stomach and one third of the proximal small intestine. In patient No 3,
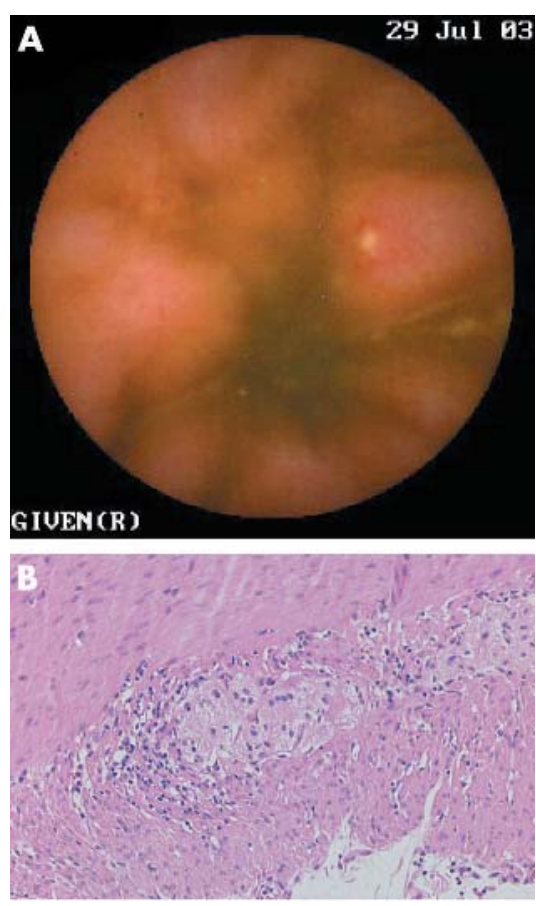

Figure 1 Patient No 3. (A) Capsule endoscopic view of the terminal ileum showing an aphthous ulceration in the ileum.

(B) Moderate lymphocytic infiltrate around and within the myenteric ganglia (haematoxylineosin $\times 100$ ). capsule enteroscopy showed aphthous ulcers typical of Crohn's disease throughout the distal jejunum and ileum (fig $1 \mathrm{~A}$ ). Ileocolonoscopy showed the same picture in the ileum and ileorectal anastomosis.

Histopathological examination of the full thickness biopsies from patient Nos 1 and 2 showed visceral degenerative neuropathy, combined with vacuolisation of the interstitial cells of Cajal (ICCs). In patient Nos 3 and 6 , lymphocytic ganglioneuronitis was found in both neural plexa of the resected colon and ileum (fig 1B), with signs of neurone degeneration, and $50 \%$ and $80 \%$ reduction of ICCs in the perimyenteric ICC-plexus and deep muscular plexus of the circular muscle layer, respectively. Patient No 4 had a normal biopsy, and patient No 5 was not biopsied. Examination of mucosal biopsies from patient No 1 revealed focal active inflammation in the duodenum and caecum, and chronic inflammation in the rectum; patient No 5 had multifocal mild antral cryptitis, and both patients were diagnosed with suspected Crohn's disease. Colon biopsies from patient No 6 revealed epithelioid cell granulomas and multinucleated giant cells, as well as multifocal transmural lymphoid hyperplasia consistent with Crohn's disease.

In three patients (Nos 1, 3, and 4), dysmotility preceded the mucosal changes. In patient Nos 2 and 5, these two entities occurred simultaneously, while in patient No 6, dysmotility developed after proctocolectomy. Ganglionitis in patient No 3 could have been caused by Crohn's disease before other symptoms of the disease developed. Treatment with 5-ASA has reduced her abdominal pain. The normal histology of the sigmoideum in patient No 4 does not exclude the possibility of ganglionitis in other parts of the bowel due to the known patchy involvement of the gut in Crohn's disease.

The present observations indicate that apart from inflammation, even purely degenerative neuronal and ICCs changes seen in CIIP can occur in patients who also have IBD/ an IBD-like condition. At present, it is not known whether the observed abnormalities are part of IBD or independent of each other. This small patient sample prevents us from drawing any definite conclusion regarding this question. Further observations are needed to establish whether or not this connection is causal.

\section{B Ohlsson}

Department of Medicine, Malmö University Hospital, University of Lund, Sweden
F-T Fork

Department of Diagnostic Radiology, Malmö University Hospital, University of Lund, Sweden

B Veress

Department of Pathology, Malmö University Hospital, University of Lund, Sweden

E Toth

Department of Medicine, Malmö University Hospital, University of Lund, Sweden

Correspondence to: $\operatorname{Dr} B$ Ohlsson, Department of Medicine, Entrance 35, 20502 Malmö, Sweden; bodil.ohlsson@kir.lu.se

doi: 10.1136/gut.2004.058826

Conflict of interest: None declared.

\section{References}

1 Patel R, Christensen J. Chronic intestinal pseudo-obstruction: Diagnosis and treatment. The gastroenterologist, 1995;3:345-56.

2 De Giorgio R, Sarnelli G, Corinaldesi R, et al. Advances in our understanding of the pathology of chronic intestinal pseudo-obstruction. Gut 2004;53:1549-52.

3 Lindgren S, Lijla B, Rosén I, et al. Disturbed autonomic nerve function in patients with Crohn's disease. Scand J Gastroenterol 1991;26:523-8.

4 Isgar B, Harman M, Kaye MD, et al. Symptoms of irritable bowel syndrome in ulcerative colitis in remission. Gut 1983;24:190-2.

5 Dvorak AM, Osage JE, Monahan RA, et al. Crohn's disease: transmission electron microscopic studies. III. Target tissues. Proliferation of and injury to smooth muscle and the autonomic nervous system. Hum Pathol 1980;11:620-34.

6 Manousos ON, Salem SN. Abnormal motility of the small intestine in ulcerative colitis. Gastroenterology 1965;104:249-57.

7 Rao SSC, Read NW, Brown C, et al. Studies on the mechanism of bowel disturbance in ulcerative colitis. Gastroenterology 1987:93:934-40.

8 Stanghellini V, Camilleri M, Malagedala J-R. Chronic idiopathic intestinal pseudo-obstruction: clinical and intestinal manometric findings. Gut 1987;28:5-12

9 Mann SD, Debinski HS, Kamm MA. Clinical characteristics of chronic idiopathic intestinal pseudo-obstruction in adults. Gut 1997;41:675-81.

10 Gourtsoyiannis N, Papanikolaou N Grammatikakis J, et al. MR eneteroclysis: technical considerations and clinical applications. Eur Radiol 2002;12:2651-8. 


\section{Cannabinoid hyperemesis: not just a problem in Adelaide Hills}

We read the article by Allen and colleagues (Gut 2004;53:1566-70) with interest and would like to report a case of probable cannabinoid hyperemesis seen in a district general hospital in the UK.

A 21 year old chef was admitted to our hospital on seven occasions over a two year period (April 2001 to December 2002) with profuse vomiting. Apart from a history of migraine as a child, he was fit and well. He smoked cannabis. Physical examination was unremarkable. The observation that the patient wanted to take regular baths because he had found that bathing eased the sickness was documented in the nursing notes but its significance was not appreciated. Investigations during attacks disclosed neutrophilia but blood urea, electrolytes, liver biochemistry, and serum amylase were normal. Abdominal $x$ ray was also normal. Upper gastrointestinal endoscopy showed grade I oesophagitis and gastritis. Gastric biopsies were histologically normal. An abdominal ultrasound scan and small bowel barium follow through examination were normal. Additional normal or negative investigations included: autoantibodies and immunoglobulins, C reactive protein, and urinary porphyrin screen. Computed tomography scan of the brain was also normal.

During his last admission, the patient's girlfriend showed us an article published in an Australian newsletter which she had obtained via the internet, in which $\mathrm{Dr} \mathrm{JH}$ Allen had raised the possibility of a link between recurrent vomiting and cannabis abuse. With the aid of the internet we traced and contacted Dr Allen who shared his experience of this condition with us.

Reviewing the patient's history, he freely admitted to smoking cannabis and experiencing the compulsive desire to bathe during bouts of vomiting. Following his last admission in December 2002, our patient stopped smoking cannabis and has remained free of symptoms. The clinical presentation which is almost identical to the cases described by Allen et al, together with the response to cessation of smoking cannabis, supports the view that our patient was suffering from cannabinoid hyperemesis and that this condition is international.

E Roche, P N Foster Macclesfield District General Hospital, Macclesfield Cheshire, UK

Correspondence to: Dr E Roche, Macclesfield District General Hospital, Victoria Rd, Macclesfield, Cheshire SK10 3BL, UK; enrico.roche@ntlworld.com

Conflict of interest: None declared.

\section{Inflammatory bowel disease stimulates formation of carcinogenic $\mathrm{N}$-nitroso compounds}

In patients with inflammatory bowel disease (IBD), an increased incidence of colorectal cancer is observed. ${ }^{1}$ Although severe inflammatory conditions per se represent a risk factor for neoplasia, we would like to draw attention to the possible role of increased activity of inducible nitric oxide synthase (iNOS), as found in IBD patients, ${ }^{2}$ in the endogenous formation of carcinogenic $N$-nitroso compounds (NOC). In healthy

Table 1 Faecal $\mathrm{N}$-nitrosodimethylamine (NDMA) concentrations in patients with inflammatory bowel disease (IBD) and in healthy controls

\begin{tabular}{lllll}
\hline & $\begin{array}{l}\text { Controls } \\
(\mathbf{n}=17)\end{array}$ & $\begin{array}{l}\text { All IBD cases } \\
(\mathbf{n}=17)\end{array}$ & $\begin{array}{l}\text { Non-hospitalised cases } \\
(\mathbf{n}=10)\end{array}$ & $\begin{array}{l}\text { Hospitalised cases } \\
(\mathbf{n}=7)\end{array}$ \\
\hline \%NDMA positive & 35 & 41 & 56 & 25 \\
NDMA (ng/g) & 1.4 & $10.9 \dagger$ & $14.3+\dagger$ & $2.4 \ddagger$ \\
\hline
\end{tabular}

${ }^{*}$ Average concentration of NDMA positive samples.

$\dagger \mathrm{p}<0.05,+\uparrow \mathrm{p}<0.01$ : significantly higher compared with the control group (Mann-Whitney U test).

$\neq \mathrm{p}<0.05$ : significantly lower compared with non hospitalised cases (Mann-Whitney $U$ test).

individuals, relatively small amounts of NOC are formed by the interaction between NOC precursors (NOCP), present in dietary items such as meat and fish, and nitrosating agents derived from dietary nitrate. It has been proposed that endogenous formation of NOC may explain the link between meat consumption and colon cancer risk found in epidemiological studies. ${ }^{3}$ We hypothesised that as a result of chronic inflammatory conditions in the large intestine, increased colonic iNOS activity may produce an excess of NO, nitrogen oxides, and nitrite, which in turn react with NOCP present in the colon to produce relatively high levels of NOC. Increased formation of NOC in IBD patients may thus contribute to the relatively high incidence of colorectal cancer associated with this disease.

A recent population based case control study showed that in cases with a history of IBD, increased exposure to drinking water nitrate was associated with an increased risk of colon cancer whereas no such association was found in the overall population. ${ }^{4}$ This clearly indicates that the risk of colon cancer in IBD patients is not only determined by the disease itself but dietary factors known to influence the endogenous formation of NOC are also associated with an increased risk in these patients. Although both the increased formation of NOC found in mice with chemically induced colitis ${ }^{5}$ and increased levels of NO and nitrite found in the colonic lumen of patients with ulcerative colitis ${ }^{6}$ support this hypothesis, faecal NOC levels have never been investigated in IBD patients.

Therefore, we collected faecal samples from 17 patients diagnosed with ulcerative colitis and 17 healthy controls, and determined levels of $N$-nitrosodimethylamine (NDMA), a predominant carcinogenic NOC, using gas chromatography-mass spectrometry, as previously described. ${ }^{7}$ The study was approved by the medical ethics committee of the Maasland Hospital, Sittard, the Netherlands, and all patients gave their consent. In $41 \%$ of patients, we found levels of NDMA above the detection limit of $1 \mathrm{ng} / \mathrm{g}$ faeces, compared with $35 \%$ of controls. Comparison of concentrations in NDMA positive samples showed that the average concentration in patients was significantly higher than that in the control group (table 1). When IBD patients were subdivided into hospitalised and nonhospitalised cases, the difference between the non-hospitalised group and controls was even more pronounced, whereas NDMA concentrations in hospitalised patients and controls were comparable. As all hospitalised patients received only liquid nutrition (Nutrison; Nutricia, UK) without additional intake of NOCP rich dietary foods, these results confirm that the combination of high dietary NOCP intake and inflammation may present a risk factor.

Most research on endogenous NOC exposure has focused predominantly on the intragastric formation of these compounds in relation to the gastric cancer risk. However, we now report that faecal NDMA levels in IBD patients are considerably higher than those we reported previously in gastric juice $(0.25(0.3) \mathrm{ng} / \mathrm{g}){ }^{7}$, which indicates that NOC exposure may be even more relevant in colon carcinogenesis.

Based on these results, we conclude that the colon of IBD patients is exposed to relatively high concentrations of this carcinogenic compound, probably as a direct consequence of continuous NO production by the inflammatory process. As this exposure may strongly contribute to the increased colon cancer risk associated with IBD, dietary recommendations for IBD patients, avoiding high NOCP intake, seem warranted.

T M C M de Kok

Department of Health Risk Analysis and Toxicology, University Maastricht, Maastricht, the Netherlands

L G J B Engels

Department of Gastroenterology, Maasland Hospital, Sittard, the Netherlands

E J Moonen, J C S Kleinjans

Department of Health Risk Analysis and Toxicology, University Maastricht, Maastricht, the Netherlands

Correspondence to: Dr T M C M de Kok, Department of Health Risk Analysis and Toxicology, University Maastricht, PO Box 616, 6200 MD, Maastricht, the Netherlands; t.dekok@grat.unimaas.nl

doi: 10.1136/gut.2004.057471

Conflict of interest: None declared.

\section{References}

1 Lashner BA, Hanauer SB, Silverstein MD. Optimal timing of colonoscopy to screen cancer in ulcerative colitis. Ann Intern Med 1988; 108:274-8.

2 Kimura H, Hokari R. Miura S, et al. Increased expression of an inducible isoform of nitric oxide synthase and the formation of peroxynitrite in colonic mucosa of patients with active ulcerative colitis. Gut 1996:42:180-7.

3 Bingham SA, Pignatelli B, Pollock JR, et al. Does increased endogenous formation of $\mathrm{N}$-nitroso compounds in the human colon explain the association between red meat and colon cancer. Carcinogenesis 1996:17:515-23.

4 De Roos AJ, Ward, MH, Lynch CF, et al. Nitrate in public water supplies and the risk of colon and rectum cancers. Epidemiology 2003;14:640-9.

5 Mirvish SS, Haorah J, Zhou L, et al. N-Nitroso compounds in the gastrointestinal tract of rats and in the feces of mice with induced colitis or fed hot dogs or beef. Carcinogenesis 2003;24:595-603.

6 Roediger WEW, Lawson MJ, Radcliffe BC. Nitrite from inflammatory cells: A cancer risk factor in ulcerative colitis. Dis Colon Rectum 1990;33:1034-6.

7 Vermeer ITM, Engels LGJB, Pachen DMFA, et al. Intragastric volatile $\mathrm{N}$-nitrosamines, nitrite, and $\mathrm{pH}$, and Helicobacter pylori during long-term treatment with omeprazole. Gastroenterology $2001 ; 121: 517-25$ 


\section{Hepatocellular carcinoma occurring after successful treatment of childhood cancer with high dose chemotherapy and radiation}

Hepatocellular carcinoma (HCC) is one of the world's most common malignancies and accounts for more than $90 \%$ of all primary liver cancers. A number of different risk factors have been identified for the development of HCC. ${ }^{1}$ Hepatitis B carrier state, environmental toxins, chronic hepatitis C virus infection, hereditary haemochromatosis, and liver cirrhosis of almost any cause are well known risk factors for HCC. In addition, environmental toxins such as aflatoxins and contaminated drinking water may contribute to the pathogenesis of HCC, especially in Asia and underdeveloped countries. Finally, a number of HCC cases have occurred after the use of thorotrast for diagnostic procedures, and survivors of the atomic bomb of Hiroshima were also at higher risk for HCC development, ${ }^{2}$ indicating that radiation might also induce the development of HCC. Herein we describe a rare case of HCC occurring in a patient 17 years after successful treatment of peripheral neuroectodermal tumour (PNET)

A 32 year old female presented with pain in the right upper quadrant of her abdomen. Seventeen years prior to presentation in our hospital this patient was treated for a PNET with a combination of high dose chemotherapy (vincristine, adriablastin, ifosfamide, and actinomycin D) and surgical removal of the $10 \times 5 \mathrm{~cm}$ tumour from her right chest followed by combined radiation (60 Gy) and chemotherapy. There were no signs of any recurrence of the tumour observed on her last check up 12 month earlier. Physical examination of the patient in our clinic showed typical signs of late radiation damage (erythema of the skin and an underdeveloped right breast) (fig 1). A firm 3-5 cm mass was palpable at the lower edge of the liver. Laboratory tests showed elevated $\alpha$-fetoprotein $(41881 \mu \mathrm{g} / \mathrm{l})$. Hepatitis serology was negative and there was no evidence of any other liver disease. Magnetic resonance imaging revealed multiple intrahepatic masses up to $6.5 \mathrm{~cm}$. A biopsy from the hepatic tumour was taken and confirmed the clinical diagnosis of HCC. The patient died three months after the diagnosis was made.

To the best of our knowledge, secondary HCC following high dose chemotherapy has never been described and therefore we searched the German Childhood Cancer

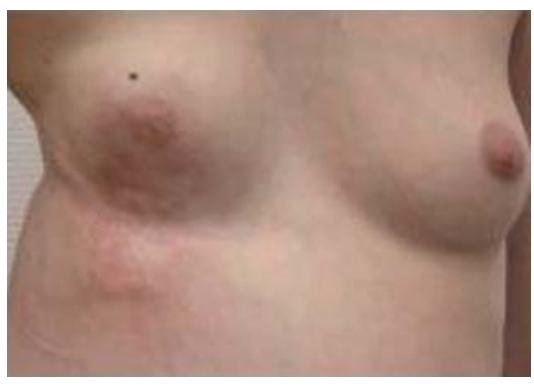

Figure 1 Thorax and upper abdomen of the patient, 17 years after radiation with $60 \mathrm{~Gy}$ and removal of the peripheral neuroectodermal tumour.

Table 1 Details of five cases of secondary hepatocellular carcinoma

\begin{tabular}{lrlll}
\hline First malignancy & $\begin{array}{c}\text { Age } \\
\text { (y) }\end{array}$ & Treatment & $\begin{array}{l}\text { Age when HCC } \\
\text { was diagnosed }(y)\end{array}$ & $\begin{array}{l}\text { Time from first to } \\
\text { second malignancy } \\
\text { (y) }\end{array}$ \\
\hline ALL & 4 & CTx* & 20 & 15 \\
Osteosarcoma & 9 & CTx, RTx & 18 & 9 \\
ALL & 4 & na & 10 & 5 \\
PNET & 15 & CTx, RTx, & 33 & 18 \\
Teratoma & 2 & na & 19 & 16 \\
\hline
\end{tabular}

ALL, acute lymphocytic leukaemia; PNET, peripheral neuroectodermal tumour; CTx, chemotherapy; RTx, radiation therapy.

*This patient was hepatitis B surface antigen positive.

registry, ${ }^{3}$ which started to register all cases of malignancies in children $(<15$ years $)$ in 1980. This database also collects data from secondary malignancies following chemotherapy. In this database we were able to detect a total of four more cases of secondary HCC, which are summarised in table 1 . Interestingly one patient was hepatitis B surface antigen positive.

Radiotherapy has been shown to be associated with an increased risk of solid tumours $10-15$ years after treatment and later. ${ }^{4}$ There is one report in the literature of a radiation induced hepatoma in a patient with a nonmalignant hepatic haemangioma, ${ }^{5}$ which occurred 20 years after radiation of the liver with 28.5 Gy. To date, the molecular mechanism of hepatocarcinogenesis is not completely understood. The main causative agentshepatitis B virus, hepatitis C virus, and aflatoxin $\mathrm{Bl}$-have been identified, which together are responsible for approximately $80 \%$ of all HCC in humans. This series of cases clearly supports the notion that secondary HCC can follow not only radiation therapy of children but also high dose chemotherapy, and may prompt careful follow up examinations of the liver in patients with a possible risk for the development of HCC.

T F Greten, M P Manns Department of Gastroenterology, Hepatology, and Endocrinology, Medizinische Hochschule Hannover, Germany

I Reinisch, P Kaatsch

German Childhood Cancer Registry, Institute for Medical Biometrics, Epidemiology and Informatics, University of Mainz, Germany

Correspondence to: $\operatorname{Dr} T \mathrm{~F}$ Greten, Department of Gastroenterology, Hepatology, and Endocrinology, Medizinische Hochschule Hannover, Carl-Neuberg Str 1, 30625 Hannover, Germany; greten.tim@mh-hannover.de

doi: 10.1136/gut.2004.059352

Conflict of interest: None declared.

\section{References}

1 Llovet JM, Burroughs A, Bruix J. Hepatocellular carcinoma. Lancet 2003;362:1907-17.

2 Thompson DE, Mabuchi K, Ron E, et al. Cancer incidence in atomic bomb survivors. Part II: Solid tumors, 1958-1987. Radiat Res 1994;137/suppl 2): $517-67$.

3 Kaatsch P, Haaf G, Michaelis J. Childhood malignancies in Germany - methods and results of a nationwide registry. Eur $J$ Cancer 1995; 31:993-9.

4 Klein G, Michaelis J, Spix C, et al. Second malignant neoplasms after treatment of childhood cancer. Eur J Cancer 2003;39:808-17.
5 Moore TA, Ferrante WA, Crowson TD. Hepatoma occurring two decades after hepatic irradiation. Gastroenterology 1976;71:128-32.

\section{Biologics in inflammatory disease: infliximab associated risk of lymphoma development}

In their excellent overview of currently available biologic compounds that are in use or under investigation for Crohn's disease (CD), Sandborn and Faubion (Gut 2004;53:1366-73) reconfirm the unique standing of infliximab. They also note the ongoing discussion concerning the increased occurrence of lymphoproliferative disorders in patients who received infliximab.

Recently, we followed a 61 year old patient with a 31 year history of relapsing CD. Initial treatment was with steroids but after 10 years a right sided hemicolectomy necessitated discontinuation of steroids. Five years before the present admission, the patient relapsed with multiple rectovesicular fistulas. Non-Hodgkin lymphoma was absent in the histologic material. Because of a poor response to conventional treatment, including azathioprine (100-200 mg/day), infliximab was added 22 months before the current admission. Total infliximab therapy included three doses of $400 \mathrm{mg}(5 \mathrm{mg} / \mathrm{kg}$ ) within two months and resulted in a marked reduction of CD activity (azathioprine was maintained). On admission 10 months after the last infliximab infusion, the patient relapsed again with ulcerations and multiple rectorectal fistulas. Biopsies showed a polymorphous tumour infiltrate. Tumour cells were positive for $\mathrm{CD} 30$ and negative for $\mathrm{T}$ and $\mathrm{B}$ cell markers as well as the anaplastic large cell lymphoma kinase (ALK) and EpsteinBarr virus (EBV) associated proteins. A multiplex polymerase chain reaction approach revealed a clonal $\mathrm{T}$ cell population and an oligoclonal B cell population. Based on these results, the diagnosis was ALK negative anaplastic large cell lymphoma with null/T cell phenotype. Clinical stage was IAE. CHOP-chemotherapy resulted in complete clinical and histological remission, which was evidenced by computer tomography, positron emission tomography, and negative rectal histology. Polymerase chain reaction analysis of the rectal biopsies revealed no $\mathrm{T}$ cell receptor rearrangement.

Three months later, the patient presented with postobstructive pneumonia. Transbronchial biopsies showed a diffuse large B cell lymphoma. In contrast with the preceding rectal biopsies, bronchial tumour cells were positive for CD20. EBER, EBNA2, and LMP-1, indicating EBV infection of latency type III, were detected in tumour cells. 
Table 1 Patients with infliximab therapy and development of lymphoma

\begin{tabular}{|c|c|c|c|c|}
\hline Case & $\begin{array}{l}\text { Age }(y) \text {, sex, } \\
\text { disease }\end{array}$ & $\begin{array}{l}\text { Dose; No of } \\
\text { infusions }\end{array}$ & Lymphoma & EBV \\
\hline $1^{1}$ & $77, M, N R$ & NR & Burkitt lymphoma & NR \\
\hline $2^{1}$ & NR & NR & Hodgkin lymphoma & NR \\
\hline $3^{1}$ & $43, F, N R$ & NR & Hodgkin lymphoma & NR \\
\hline $4^{1}$ & $34, M, N R$ & NR & DLBCL & Positive \\
\hline $5^{1}$ & $70, M, N R$ & NR & DLBCL & NR \\
\hline $6^{1}$ & $29, M, C D$ & $5 \mathrm{mg} / \mathrm{kg} ; 3$ & Hodgkin lymphoma & NR \\
\hline $7^{1}$ & $68, F, N R$ & NR & B cell NHL & NR \\
\hline $8^{1}$ & $62, M, N R$ & NR & DLBCL & NR \\
\hline $9^{1}$ & $73, M, N R$ & NR, multiple, & Mantle cell lymphoma & NR \\
\hline $10^{2}$ & $74, F, R A$ & $10 \mathrm{mg} / \mathrm{kg} ; 8$ & $\mathrm{~B}$ cell NHL & NR \\
\hline $11^{2}$ & $48, M, R A$ & $10 \mathrm{mg} / \mathrm{kg} ; 2$ & B cell NHL & NR \\
\hline $12^{2}$ & $59, \mathrm{~F}, \mathrm{RA}$ & $3 \mathrm{mg} / \mathrm{kg} ; 5$ & Multiple myeloma & NR \\
\hline $13^{2}$ & $61, M, R A$ & $1 \mathrm{mg} / \mathrm{kg} ; 1$ & Hodgkin lymphoma & NR \\
\hline $14^{2}$ & $36, M, C D, H I V$ & $10 \mathrm{mg} / \mathrm{kg} ; \mathrm{NR}$ & $\mathrm{B}$ cell NHL & NR \\
\hline $15^{23}$ & $62, M, C D$ & $10 \mathrm{mg} / \mathrm{kg} ; 1$ & Intravascular B-NHL & NR \\
\hline $16^{4}$ & $48, F, D M$ & $5 \mathrm{mg} / \mathrm{kg} ; 3$ & DLBCL & NR \\
\hline $17^{5}$ & $\begin{array}{l}\text { 47, M, } \\
\text { Psoriasis }\end{array}$ & $6 \mathrm{mg} / \mathrm{kg} ; 3$ & CD30+ T-cell lymphoma & Negative \\
\hline $18^{6}$ & $70, M, C D$ & $5 \mathrm{mg} / \mathrm{kg} ; 3$ & Follicular lymphoma & NR \\
\hline $19^{6}$ & $51, M, C D$ & $5 \mathrm{mg} / \mathrm{kg}, 4$ & Hodgkin lymphoma & NR \\
\hline $20^{7}$ & $25, M, C D$ & $5 \mathrm{mg} / \mathrm{kg}, 1$ & NK cell lymphoma & NR \\
\hline $21^{7}$ & $79, M, C D$ & $5 \mathrm{mg} / \mathrm{kg}, 1$ & $\mathrm{~B}$ cell NHL & NR \\
\hline $22^{7}$ & $24, F, C D$ & $5 \mathrm{mg} / \mathrm{kg}, \mathrm{NR}$ & B cell NHL & NR \\
\hline $23^{8}$ & NR, RA & NR & DLBCL & NR \\
\hline $24^{8}$ & NR, RA & NR & Mixed cell NHL & NR \\
\hline $25^{8}$ & NR, RA & NR & B cell NHL & NR \\
\hline $26^{8}$ & NR, RA & NR & B cell NHL & NR \\
\hline $27^{8}$ & NR, RA & NR & $\mathrm{B}$ cell $\mathrm{NHL}$ & NR \\
\hline $28^{8}$ & NR, RA & NR & DLBCL & NR \\
\hline $29^{8}$ & NR, RA & NR & Lymphocytic NHL & NR \\
\hline $30^{8}$ & NR, RA & NR & Low grade NHL & NR \\
\hline $31^{8}$ & NR, RA & NR & Mixed cell NHL & NR \\
\hline $33^{9}$ & $N R, C D$ & $5 \mathrm{mg} / \mathrm{kg}, 1$ & NK cell lymphoma & NR \\
\hline 34 & $61, M, C D$ & $10 \mathrm{mg} / \mathrm{kg}, 3$ & Metachronous lymphoma (ALCL, DLBCL) & Positive \\
\hline
\end{tabular}

$\mathrm{ALCL}$, anaplastic large cell lymphoma, CD, Crohn's disease, DLBCL, diffuse large B cell lymphoma, DM, dermatomyositis, NHL, non-Hodgkin lymphoma, NR, not reported, RA, rheumatoid arthritis.

However, tumour cells were negative for CD30 and ALK protein. Molecular analysis demonstrated a monoclonal immunoglobulin heavy chain rearrangement in the absence of a $\mathrm{T}$ cell receptor rearrangement, confirming the diagnosis. The tumour was neither responsive to CHOP-Rituximab nor to the ensuing second and third line chemotherapies. When the patient presented for fourth line chemotherapy, spontaneous partial remission was seen, persisting now for 10 months up to the last clinical follow up in September 2004.

As mentioned by Sandborn and Faubion, the 33 published $\operatorname{cases}^{1-9}$ (table 1) of lymphomas following infliximab therapy raise the question of a contributory role of infliximab in the propagation of lymphoproliferative disorders.

We can now add a unique case of a metachronous duplex non-Hodgkin lymphoma of initially $\mathrm{T}$ and then $\mathrm{B}$ cell phenotype. Imbalanced function of $\mathrm{T}$ lymphocytes may have acted as a key feature in this patient as the development of $\mathrm{CD}$ and the EBV related B cell non-Hodgkin lymphoma were both closely related to $\mathrm{T}$ lymphocytes. This links the case to infliximab as proapoptotic effects on $\mathrm{T}$ lymphocytes caused by infliximab have been described. Therefore, the recommendation to routinely give infliximab maintenance therapy and concomitant immunosuppressive treatment to minimise the formation of antichimeric antibodies seems to carry a theoretical risk of elevating the incidence of lymphoma above the background rate. Infliximab was approved by the US Federal Drug Administration five years ago, and up until April 2004 approximately 500000 patients have been treated. Based on medwatch data, an incidence of non-Hodgkin lymphoma of 6.6/100 000 treated patients was estimated in 2002, which still seems valid if compared with published cases. However, our current knowledge does not allow definitive conclusions to be drawn about the association of infliximab and lymphoma.

C Bucher

Department of Internal Medicine, University Hospital, Basel, Switzerland

L Degen

Department of Gastroenterology, University Hospital, Basel, Switzerland

S Dirnhofer

Institute of Pathology, University Hospital, Basel,

Switzerland

M Pless, R Herrmann

Department of Oncology, University Hospital, Basel,

Switzerland

P Schraml, P Went

Institute of Pathology, University Hospital, Basel,

Switzerland

Correspondence to: Dr P Went, Institute of Pathology, University of Basel, Schönbeinstrasse $40, \mathrm{CH}-4031$ Basel, Switzerland; pwent@uhbs.ch

Conflict of interest: None declared.

\section{References}

1 Brown SL, Greene MH, Gershon SK, et al. Tumor necrosis factor antagonist therapy and lymphoma development: twenty-six cases reported to the Food and Drug Administration. Arthritis Rheum 2002;46:3151-8.

2 Bickston SJ, Lichtenstein GR, Arseneau KO, et al. The relationship between infliximab treatment and lymphoma in Crohn's disease. Gastroenterology 1999; 117:1433-7.

3 Rutgeerts P, D'Haens G, Targan S, et al. Efficacy and safety of retreatment with anti-tumor necrosis factor antibody (infliximab) to maintain remission in Crohn's disease. Gastroenterology 1999; 117:761-9.

4 Roddy E, Courtney PA, Morris A. Non-Hodgkin's lymphoma in a patient with refractory dermatomyositis which had been treated with infliximab. Rheumatology (Oxford) 2002:41:1194-5.

5 Mahe E, Descamps V, Grossin M, et al. CD30+ Tcell lymphoma in a patient with psoriasis treated with ciclosporin and infliximab. Br J Dermatol 2003; 149:170-3.

6 Colombel JF, Loftus EV Jr, Tremaine WJ, et al. The safety profile of infliximab in patients with Crohn's disease: the Mayo clinic experience in 500 patients. Gastroenterology 2004;126:19-31.

7 Liung T, Karlen P, Schmidt D, et al. Infliximab in inflammatory bowel disease: clinical outcome in a population based cohort from Stockholm County. Gut 2004,53:849-53.

8 Wolfe F, Michaud K. Lymphoma in rheumatoid arthritis: the effect of methotrexate and anti-tumor necrosis factor therapy in 18,572 patients. Arthritis Rheum 2004;50:1740-51.

9 Hanaver SB, Feagan BG, Lichtenstein GR, et al. Maintenance infliximab for Crohn's disease: the ACCENT I randomised trial. Lancet

2002;359:1541-9.

\section{Genotypes 677TT and $677 C T+1298 A C$ of methylenetetrahydrofolate reductase are associated with the severity of ulcerative colitis in central China}

Increased blood levels of homocysteine have been found to be associated with inflammatory bowel diseased (IBD) in several studies. ${ }^{12}$ The main genetic determinant associated with elevated plasma levels of homocysteine (t-Hcys) is the MTHFR $677 C \rightarrow T$ gene polymorphism of methylenetetrahydrofolate reductase, a critical enzyme involved in the remethylation pathway of homocysteine. ${ }^{3}$ An association of the MTHFR $677 T$ allele with IBD has been reported in Northern Europe ${ }^{14}$ but not in three other series from Italy and France. ${ }^{5-7}$ Double heterozygosity MTHFR 677CT+1298AC also produces reduced enzyme activity and increased t-Hcys, but its association with IBD has never been studied. Similarly, the association of IBD with transcobalamin $(T C N 1 \quad 776 C \rightarrow G)$, a genetic determinant that influences transcobalamin levels and t-Hcys, is not known. Transcobalamin is the protein that promotes intestinal transcytosis and cell delivery of vitamin $\mathrm{B} 12$, the cofactor of the methionine synthase dependent remethylation pathway. ${ }^{8}$

In this study, we have evaluated the association of ulcerative colitis (UC) with MTHFR $677 C \rightarrow$ T, MTHFR $1298 A \rightarrow C$, and TCN1 $776 C \rightarrow G$ in a series of 72 patients from central China who gave informed consent. This series was compared with 111 age and sex matched controls. The research protocol was approved by the local appointed committee. Extraction of DNA and determination of polymorphisms were performed as described previously by us. ${ }^{89}$ A continuity corrected $\chi^{2}$ test and an ANOVA test were used, respectively, to assess differences in categorical and continuous variables between groups. Odds ratios of independent categorical variables 
Table 1 Clinical characteristics and methylenetetrahydrofolate reductase (MTHFR) and transcobalamin (TCN) polymorphisms in 72 patients with ulcerative colitis (UC) and 111 controls from central China

\begin{tabular}{|c|c|c|c|}
\hline & $\begin{array}{l}\text { Ulcerative } \\
\text { colitis }\end{array}$ & Controls & $\mathrm{p}$ Value \\
\hline$n$ & 72 & 118 & \\
\hline $\operatorname{Sex}(F / M)$ & $35 / 37$ & $58 / 60$ & 0.9423 \\
\hline Age (y) (mean (SD)) & $41(15)$ & 40 (13) & 0.4809 \\
\hline Age of onset (y) (mean (SD)) & $38(14)$ & & \\
\hline Current smoker (n (\%)) & $1(1.4)$ & & \\
\hline \multicolumn{4}{|l|}{ Extent of UC (n (\%)) } \\
\hline Rectum & $40(55.6)$ & & \\
\hline Left colitis & $15(20.8)$ & & \\
\hline Right colon & $1(1.4)$ & & \\
\hline Total colon & $17(23.6)$ & & \\
\hline \multicolumn{4}{|l|}{ Treatment (n (\%)) } \\
\hline 5-ASA/SASP & $53(73.6)$ & & \\
\hline Steroids & $15(20.8)$ & & \\
\hline Antibiotics & $13(18.1)$ & & \\
\hline Intestinal resections (n (\%)) & $1(1.4)$ & & \\
\hline \multicolumn{4}{|c|}{ Genetic polymorphisms (n (\%) [95\% Cl]) } \\
\hline MTHFR $667 T$ allele & $50(34.7)[27.3-42.7]$ & $91(41.0)[34.7-47.5]$ & 0.2286 \\
\hline MTHFR $677 T$ & $10(13.9)[7.2-23.0]$ & $21(18.9)[12.4-26.8]$ & 0.3707 \\
\hline MTHFR 1298 C allele & 18 (14.1) [8.8-20.7] & $41(18.5)[13.7-23.9]$ & 0.2889 \\
\hline MTHFR $677 C T+1298 A C$ & $4(6.2)[2.0-14.0]$ & 17 (15.3) [9.5-22.7] & 0.0755 \\
\hline MTHFR 677TT/CT+1298AC & $14(21.2)[12.6-32.0]$ & 38 (34.2) [25.9-43.3] & 0.0659 \\
\hline TCN $776 G$ allele & $62(63.3)[53.6-72.3]$ & $138(60.0)[53.6-66.2]$ & 0.5709 \\
\hline \multirow[t]{2}{*}{ TCN $776 C G+G G$} & 42 (85.7) [74.3-93.6] & 89 (77.4) [69.3-84.3] & 0.2236 \\
\hline & Total colon & Less extended UC & \\
\hline MTHFR 677TT+CT/1298AC & $7(43.7)[22.6-66.6]$ & $7(14.0)[6.3-25.2]$ & 0.0162 \\
\hline
\end{tabular}

that differed significantly between patients and controls were determined by logistic regression analysis. A p value $<0.05$ was considered to indicate statistical significance.

The main clinical characteristics are summarised in table 1. Most of the cases were recently diagnosed. None had any thrombotic manifestations. TCNI 776G allele frequency was approximately 1.5 -fold higher compared with Caucasians, and we failed to find any association with the risk of UC or severity of disease. MTHFR $677 T$ allele frequency in our control group was close to that reported in South Europe and much higher than that of North Europe. There was no significant association of the MTHFR 677TT or 677T allele with the risk of UC. By comparison, this association was significant in two UC series of 52 and 91 cases, respectively, from the UK and Denmark, two countries with a lower MTHFR $677 T$ allele frequency, but not in other series from Italy and France where allele frequency was comparable with that observed in our population. These discrepant results could therefore be related, at least in part, to ethnic variations in $677 T$ allele frequency, as previously observed with Down syndrome, spina bifida, and cardiovascular diseases..$^{10}$ In contrast, we found a significant association with age at onset. Onset in 6777 allele carriers occurred later than that of non-carriers, with respective mean ages of 42.4 (15.7) and $35.4(13.8)(\mathrm{p}=0.0487)$.

Our results were different when the two $677 T T$ and 677CT+1298AC genotypes of MTHFR were considered together, that correspond to decreased catalytic activity. Firstly, the difference in frequency between patients and controls was at the limit of significance and this could be related to the limited size of our patient series (table 1). Secondly, these genotypes were associated with an increased risk of extensive UC (whole colon) (table 1), with an odds ratio of 4.92 (95\% confidence interval 1.3-18.3; $\mathrm{p}=0.017$ ), after adjustment for age and sex.

Figure 2
In conclusion, our study showed that the genotypes of MTFHR, associated with a decrease in enzyme activity, seemed to be more significantly associated with extension of disease than with the primary risk, at least in central China.

M Chen, B Xia

Department of Internal Medicine and Geriatrics, Zhongnan Hospital and Research Centre of Digestive Diseases, Wuhan University Medical School, Wuhan, RP China

R M Rodriguez-Gueant, M Bigard, J-L Gueant INSERM-0014 and Department of HepatoGastroenterology, Medical Faculty and University Hospital Centre, University of Nancy, Nancy, France

Correspondence to: Dr J-L Gueant, INSERM-0014 and Department of Hepato-Gastroenterology, Medical Faculty and University Hospital Centre, University of Nancy, Nancy, France; il.gueant@ chu-nancy.fr doi: 10.1136/gut.2004.062539 Conflict of interest: None declared.

\section{References}

1 Mahmud N, Molloy A, McPartlin J, et al. Increased prevalence of methylenetetrahydrofolate reductase C677T variant in patients with inflammatory bowel disease, and its clinical implications. Gut 1999;45:389-94.

2 Papa A, Danese S, Grillo A, et al. Review article: inherited thrombophilia in inflammatory bowel disease. Am J Gastroenterol 2003;98:1247-51

3 Bollander-Gouaille C. Focus on homocysteine and the vitamins involved in its metabolism, 2nd edn., Paris: Spinger-Verlag 2002

4 Nielsen JN, Larsen TB, Fredholm L, et al. Increased prevalence of methylenetetrahydrofolate reductase C677T variant in patients with IBD. Gut 2000:47:456-7.

5 Vecchi M, Sacchi E, Saibeni S, et al. Inflammatory bowel diseases are not associated with major hereditary conditions predisposing to thrombosis Dig Dis Sci 2000:45:1465-9.

6 Papa A, De Stefano V, Danese S, et al. Hyperhomocysteinemia and prevalence of polymorphisms of homocysteine metabolismrelated enzymes in patients with inflammatory bowel disease. Am J Gastroenterol 2001:96:2677-82.

7 Guedon C, Le Cam-Duchez, Lalaude O, et al. Prothrombotic inherited abnormalities other than factor $V$ Leiden mutation do not play a role in venous thrombosis in inflammatory bowe disease. Am J Gastroenterol 2001 ;96:1448-54.

8 Namour F, Olivier JL, Abdelmouttaleb I, et al. Transcobalamin codon 259 polymorphism in HT29 and Caco-2 cells and in Caucasians: relation to transcobalamin and homocysteine concentration in blood. Blood 2001;97:1092-8.

9 Amouzou E, Chabi N, Adjalla C, et al. High prevalence of hyperhomocysteinemia related to folate deficiency and mutated $677 \mathrm{C} \rightarrow$ MTHFR, in the coast of West Africa. Am J Clin Nutr 2004;79:619-24.

10 Guéant JL, Rodriguez-Guéant RM, Anello G, et al. Genetic determinants of folates and vitamin B12 metabolisms: a common pathway in neural tube defect and Down syndrome. Clin Chem Lab Med 2003;41:1473-7.

\section{CORRECTION}

doi: 10.1136/gut.2004.045294corr 1

The original article by Cosnes et al (Impact of the increasing use of immunosuppressants in Crohn's disease on the need for intestinal surgery. Gut 2005;54:237-41), published in the February 2005 issue was incomplete. Figure 2 was missing from the proof. A corrected version of the pdf can be viewed at http://gut.bmjjournals.com/cgi/data/54/2/237/ DCl/1, and the missing figure can be seen here.

\begin{tabular}{|lll|}
\hline$\cdots-.-78-82(n=34)$ & $--83-87(n=46)$ & $--88-92(n=102)$ \\
$-93-97(n=176)$ & $-98-02(n=207)$ & \\
\hline
\end{tabular}

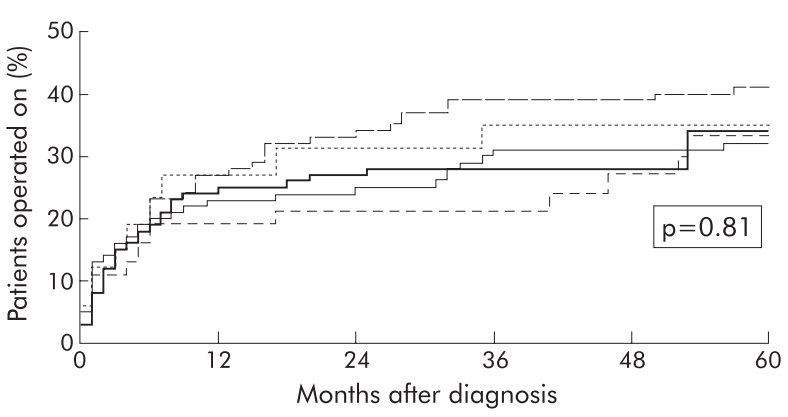

